\title{
1 Apelin signaling dependent endocardial protrusions promote cardiac trabeculation in
}

2

3

4

5

6

7 zebrafish

Jialing $\mathrm{Qi}^{1}$, Annegret Rittershaus ${ }^{3}$, Rashmi Priya ${ }^{1,2}$, Shivani Mansingh ${ }^{1}$, Didier Y.R. Stainier ${ }^{1 *}$, Christian S.M. Helker ${ }^{1,3,4^{*}}$

${ }^{1}$ Department of Developmental Genetics, Max Planck Institute for Heart and Lung Research, 61231 Bad Nauheim, Germany

${ }^{2}$ Present address:

RP: The Francis Crick Institute, Organ Morphodynamics Laboratory, London NW1 1AT, UK ${ }^{3}$ Present address:

CSMH: Philipps-University Marburg, Faculty of Biology, Cell Signaling and Dynamics, 35043 Marburg, Germany

${ }^{4}$ Lead contact

*Correspondence: christian.helker@biologie.uni-marburg.de, didier.stainier@mpi-bn.mpg.de

\section{Abstract}

During cardiac development, endocardial cells (EdCs) produce growth factors to promote myocardial morphogenesis and growth. In particular, EdCs produce Neuregulin which is required for ventricular cardiomyocytes (CMs) to seed the multicellular ridges known as trabeculae. Defects in Neuregulin signaling, or in endocardial sprouting towards $\mathrm{CMs}$, cause hypotrabeculation. However, the mechanisms underlying endocardial sprouting remain largely unknown. Here, we first show by live imaging in zebrafish embryos that EdCs interact with $\mathrm{CMs}$ via dynamic membrane protrusions. After touching $\mathrm{CMs}$, these protrusions remain in close contact with their target despite the vigorous cardiac contractions. Loss of the CM-derived peptide Apelin, or of the Apelin receptor, which is expressed in EdCs, leads to reduced endocardial sprouting and hypotrabeculation. Mechanistically, Neuregulin signaling requires endocardial protrusions to activate extracellular signal-regulated kinase (Erk) signaling in CMs and trigger their delamination. Altogether, these data show that Apelin signaling dependent endocardial protrusions modulate $\mathrm{CM}$ behavior during trabeculation.

\section{Introduction}

To meet the needs of the growing embryo, the vertebrate heart has to undergo a series of complex morphogenetic events to transform from a linear tube into a mature organ. During trabeculation, $\mathrm{CMs}$ in the outer curvature of the ventricles delaminate towards the lumen to form multicellular sponge-like projections, called cardiac trabeculae (Sedmera and Thomas, 1996; Sedmera et al., 2000; Stankunas et al., 2008; Liu et al., 2010; Peshkovsky et al., 2011; Staudt et al., 2014). Cardiac 
trabeculae are crucial to achieve increased contractility as well as for the formation of the conduction system. Trabeculation defects are often associated with left ventricular noncompaction (Oechslin et al., 2000; Claudia and Josef, 2004), embryonic heart failure, and lethality (Gassmann et al., 1995; Lee et al., 1995; Lai et al., 2010; Liu et al., 2010; Rasouli and Stainier, 2017).

In zebrafish, as in other vertebrates, the early embryonic heart consists of two monolayers of cells, the myocardium and the endocardium, that are separated by a layer of extracellular matrix (ECM) termed the cardiac jelly (CJ) (Stainier and Fishman, 1992; Brutsaert et al., 1996). Recently, it has been shown that EdCs, similar to blood endothelial cells (ECs), form sprouts, which are mostly oriented towards the myocardium (Del Monte-Nieto et al., 2018). During sprouting angiogenesis, ECs first extend filopodia to sense the microenvironment for growth factors, then they migrate into avascular areas and form new blood vessels (Gerhardt et al., 2003). Due to its similarity to sprouting angiogenesis, the sprouting of EdCs has been termed endocardial sprouting. However, whether endocardial sprouting is regulated by the same signaling pathways as sprouting angiogenesis is not known.

Multiple signaling pathways have been implicated in cardiac trabeculation, including neuregulin $(\mathrm{Nrg}) / \mathrm{ErbB}$ signaling. Mouse and zebrafish embryos lacking the endocardium derived ligand $\mathrm{Nrg}$ or the ErbB receptor, which is expressed by the myocardium, fail to form trabeculae (Gassmann et al., 1995; Lee et al., 1995; Meyer and Birchmeier, 1995; Lai et al., 2010; Liu et al., 2010; Rasouli and Stainier, 2017). Furthermore, endocardial Notch signaling (Grego-Bessa et al., 2007; D'Amato et al., 2016; Del Monte-Nieto et al., 2018), angiopoietin 1/Tie2 signaling (Suri et al., 1996; Tachibana et al., 2005; Qu et al., 2019), and semaphorin 3E (Sema3E)/plexinD1 signaling (Sandireddy et al., 2019) are required for cardiac trabeculation in mouse. Of note, genetic deletion of the relevant receptors in the endocardium results in attenuated endocardial sprouting (Qu et al., 2019) and trabeculation defects (Grego-Bessa et al., 2007; D'Amato et al., 2016; Del Monte-Nieto et al., 2018; Qu et al., 2019; Sandireddy et al., 2019).

Cells communicate by a variety of mechanisms including paracrine and contact dependent signaling. More recently, a novel mechanism of cell communication by active transport of signaling molecules through filopodia-like actin rich membrane protrusions, also known as cytonemes, has been shown in different models including Drosophila (Ramirez-Weber and Kornberg, 1999; Roy et al., 2011; Huang et al., 2019), chick (Sanders et al., 2013), zebrafish (Stanganello et al., 2015), and mouse (Fierro-Gonzalez et al., 2013). Like filopodia, cytonemes depend on actin polymerization by various effector proteins including formins, profilin and IRSp53, a substrate for the insulin receptor (Rottner et al., 2017). 
In this study, we take advantage of the zebrafish model, as its transparency allows single-cell resolution and high-speed imaging of the beating heart, to analyze endocardial-myocardial communication during embryogenesis. By investigating apelin (apln) mutants, we found that endocardial protrusion formation is controlled by Apln signaling. We also observed by in vivo imaging that endocardial protrusions promote cardiac trabeculation by modulating $\mathrm{Nrg} / \mathrm{ErbB} / \mathrm{Erk}$ signaling. Altogether, our results provide new insights into the role of endocardial protrusion during cardiac trabeculation.

\section{Results:}

\section{Endocardial-myocardial interactions in zebrafish}

The early embryonic heart is composed of two cell types: endocardial cells and myocardial cells; and in zebrafish, myocardial cells initially form a monolayer (Figure 1A-D). In order to analyze possible interactions between the endocardial and myocardial cells, we genetically labeled the actin cytoskeleton of the endocardium using the TgBAC(cdh5:Gal4ff) and Tg(UAS:LIFEACT-GFP) lines, and the membrane of cardiomyocytes with mCherry using the $\operatorname{Tg}(m y / 7: m C h e r r y-C A A X)$ line. We observed endocardial protrusions extending towards the myocardium at 24 (Figure 1A-A") and 48 (Figure 1B-B", Figure 1-figure supplement 1A) hpf. Of note, we observed more endocardial protrusions in the ventricle than in the atrium at 48,60 and $72 \mathrm{hpf}$ (Figure 1-figure supplement 1B). Subsequently, these ventricular endocardial protrusions formed anchor points with the myocardium which according to similar observations in mouse (Del Monte-Nieto et al., 2018) we refer to as touchdowns (Figure 1B-B"). Notably, these touchdowns are stable even during cardiac contractions (Figure 1E-H, Figure 1-video 1). Starting at around $60 \mathrm{hpf}, \mathrm{CMs}$ delaminate from the compact layer towards the lumen to seed the trabecular layer (Figure $1 \mathrm{C}, \mathrm{C}^{\prime}$, and $\mathrm{C}^{\prime \prime \prime \prime}$ ), as reported before (Liu et al., 2010; Staudt et al., 2014; Priya et al., 2020). We observed that endocardial protrusions appear to extend along the delaminating CMs (Figure $1 C^{\prime \prime}$ and $C^{\prime \prime \prime}$, Figure 1-video 2). Next, trabecular CMs start to assemble into trabecular units, which consist of several trabecular CMs, starting at $72 \mathrm{hpf}$ (Figure $1 D, D^{\prime}$, and $\left.D^{\prime \prime \prime \prime}\right)$. At this time point, we noticed that endocardial protrusions can be detected in close proximity to trabecular CMs (Figure 1D" and D'", Figure 1-video 3). Recently, it has been shown that endothelial protrusions modulate neurogenesis by affecting progenitor proliferation in the developing brain (Di Marco et al., 2020). To determine whether endocardial protrusions affect CM proliferation, we performed EdU labeling between 28 and $72 \mathrm{hpf}$ and analyzed the heart at $72 \mathrm{hpf}$. We observed that $54 \%$ of EdU positive CMs (total $n=24$ ) were in close proximity to endocardial protrusions (Figure 1-figure supplement 2) indicating that endocardial protrusions may modulate CM proliferation. 

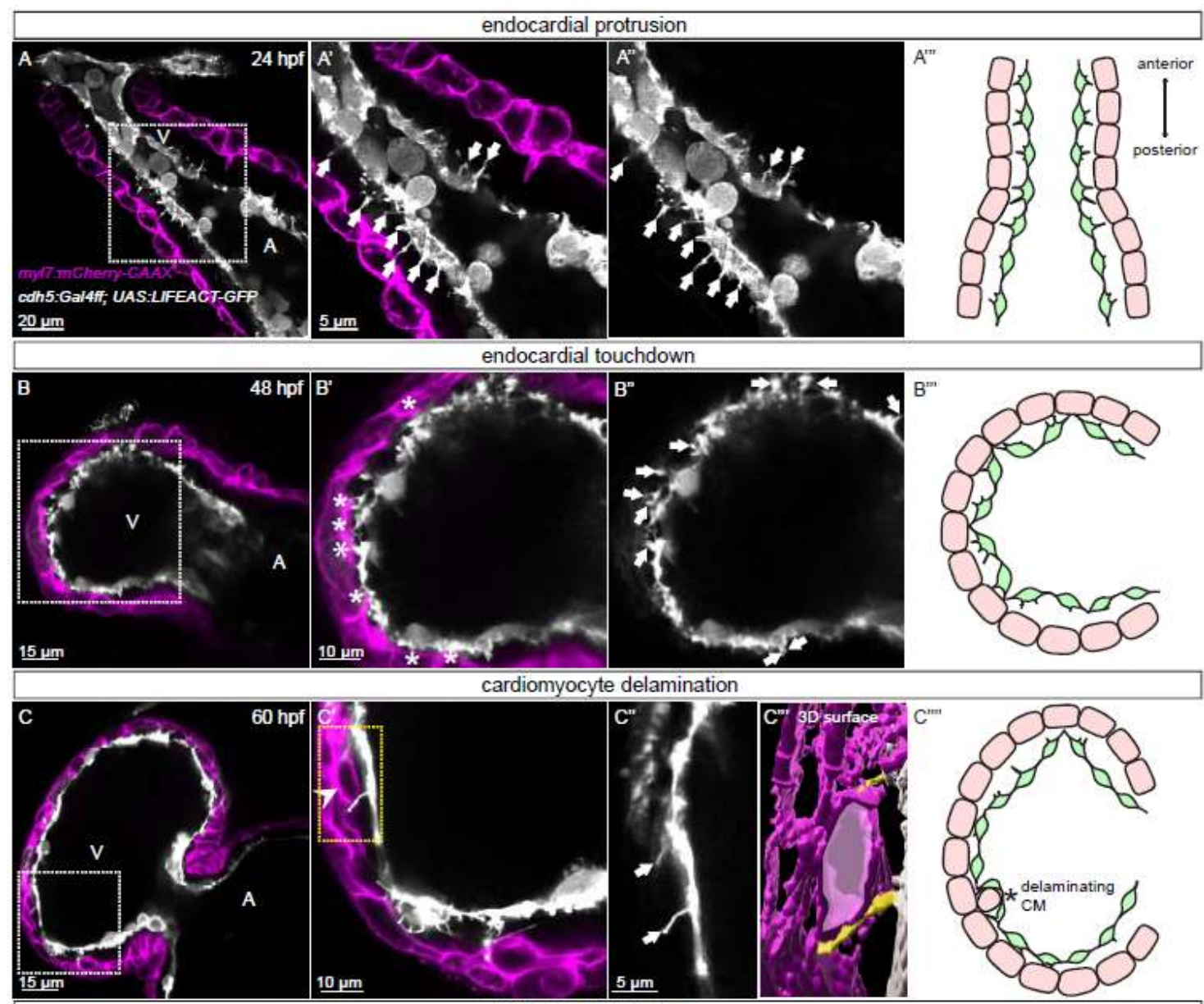

trabecular expansion

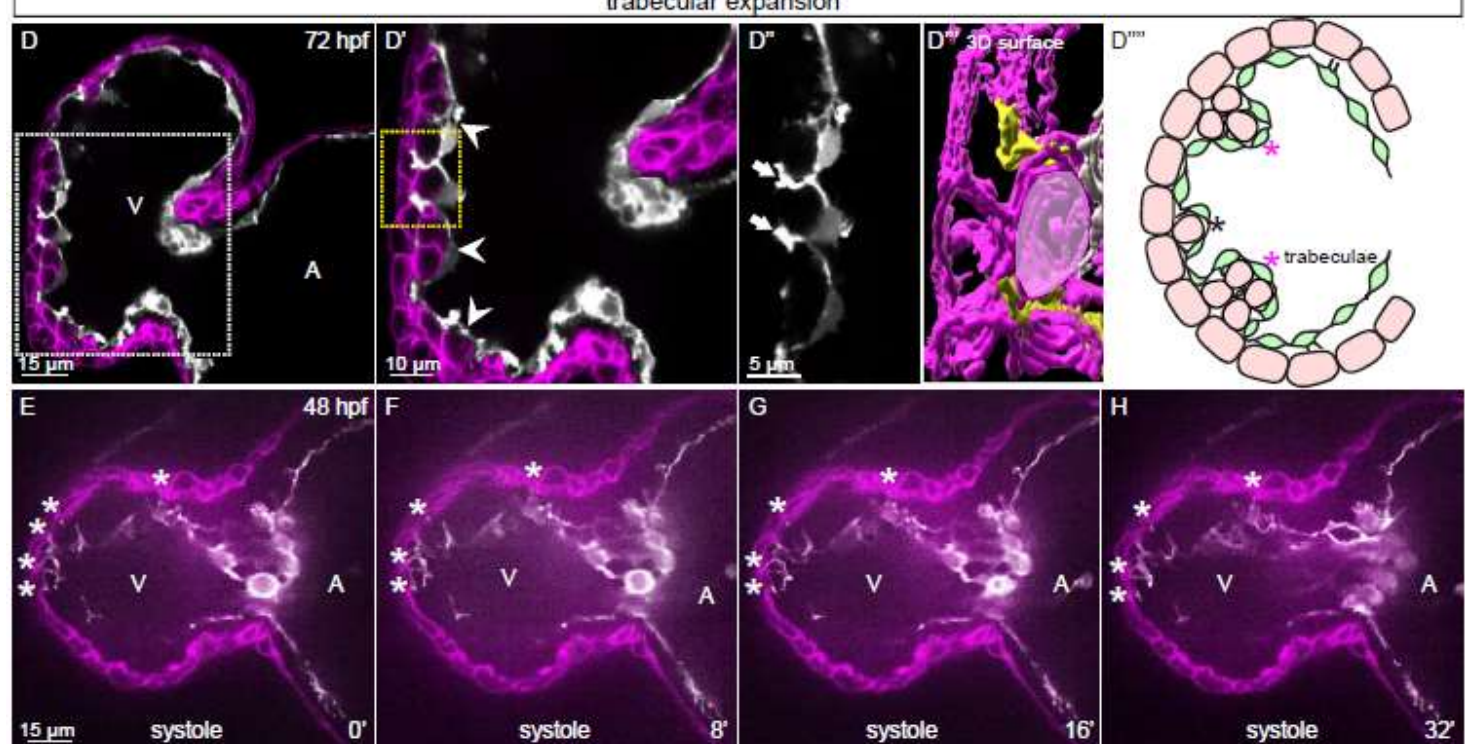

Figure 1. Endocardial-myocardial interactions during zebrafish heart development. (A-D) Confocal projection images of the heart of $T g$ (myl7:mCherry-CAAX); $T g(c d h 5: G a l 4 f f) ; T g(U A S: L I F E A C T-G F P)$ zebrafish at 24 (A), 48

101 (B), 60 (C) and 72 (D) hpf. (A-A") Endocardial protrusions (arrows) towards the myocardium at 24 hpf. (B-B")

102 Endocardial protrusions (arrows) and touchdowns (asterisks) with the myocardium at 48 hpf. (C-C'")

103 Endocardial protrusions (arrows) during CM delamination (arrowheads) at $60 \mathrm{hpf}$. (C'"') 3D surface rendering of the area in the yellow box in C'. (D-D'”') Endocardial protrusions (arrows) during trabecular assembly and expansion (arrowheads) at 72 hpf. (D'"') 3D surface rendering of the area in the yellow box in $\mathbf{D}^{\prime}$. ( $\left(\mathbf{A}^{\prime \prime \prime \prime}-\mathbf{D}^{\prime \prime \prime \prime}\right)$ 

Black asterisks indicate delaminating CMs; purple asterisks indicate trabeculae. (E-H) Still images from a spinning disc time-lapse movie of a 48 hpf $T g$ (myl7:mCherry-CAAX); Tg(cdh5:Gal4ff); Tg(UAS:LIFEACT-GFP) heart. White asterisks indicate endocardial touchdowns. All images are ventral views, anterior to the top. $\mathrm{V}$, ventricle; $A$, atrium.

\section{Genetically blocking endocardial protrusion formation reduces myocardial trabeculation}

112 Since we observed a correlation between endocardial protrusions and myocardial trabeculation, we 113 next aimed to examine the function of endocardial protrusions during cardiac morphogenesis. To 114 this aim, we generated a transgenic line, $T g\left(U A S\right.$ : irsp $\left.53^{d n}-p 2 a-R F P\right)$, to specifically block protrusion 115 formation in the endothelium. IRSp53 regulates the actin cytoskeleton to enable cells to form 116 different types of membrane extensions (Nakagawa et al., 2003; Millard et al., 2005; Scita et al., 117 2008). By crossing the $T g\left(U A S:\right.$ irsp53 $\left.{ }^{d n}-p 2 a-R F P\right)$ line to the $\operatorname{TgBAC}(c d h 5: G a l 4 f f)$ line to overexpress $118 \operatorname{Irsp} 53^{\mathrm{dn}}$ specifically in endothelial cells, we observed a 70\% reduction in the number of endocardial 119 protrusions at $48 \mathrm{hpf}$ (Figure 2A, B, and E) while their distribution appeared mostly unaffected

120 (Figure 2A, B, and F). To test the hypothesis that endocardial protrusions modulate myocardial 121 trabeculation, we analyzed embryos overexpressing irsp $53^{d n}$ in their endothelial cells in the $122 \mathrm{Tg}\left(\right.$ myl7:BFP-CAAX), a CM membrane line. Upon irsp53 ${ }^{d n}$ overexpression in ECs, we detected fewer 123 endocardial touchdowns (Figure $2 \mathrm{~A}$ and $\mathrm{B}$ ). In addition, cardiac trabeculation was reduced (Figure $1242 \mathrm{C}, \mathrm{D}, \mathrm{G}$, and $\mathrm{G}^{\prime}$ ). In order to analyze a possible effect of endocardial protrusions on CM proliferation, we overexpressed $i r s p 53^{d n}$ in the endothelium in the context of the $T g$ (myl7:mVenusgmnn) reporter to visualize cycling CMs. Compared with controls, endothelial overexpression of irsp $53^{d n}$ led to significantly fewer mVenus-Gmnn ${ }^{+} \mathrm{CMs}$ in the ventricle (Figure $2 \mathrm{H}$ and $\mathrm{I}$ ). 

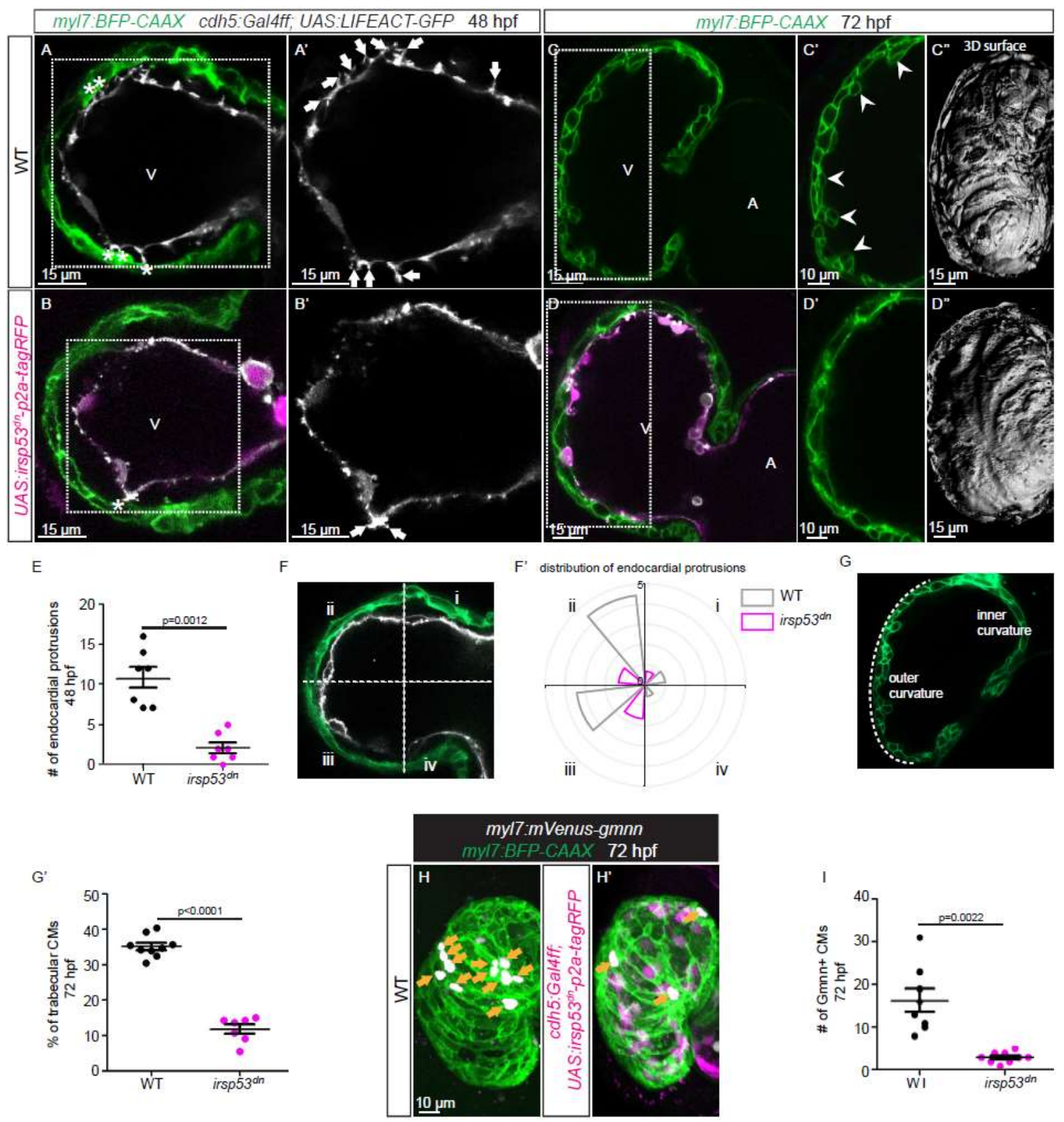

Figure 2. Blocking endocardial protrusion formation reduces cardiac trabeculation. (A-D) Confocal projection images of the heart of $T g(m y / 7: B F P-C A A X) ; T g(c d h 5: G a l 4 f f) ; T g(U A S: L I F E A C T-G F P) ;+/-T g\left(U A S: i r s p 53^{d n}\right.$-p2a$\operatorname{tagRFP)}$ zebrafish at 48 (A-B) and 72 (C-D) hpf. (A-B) Endocardial protrusions (white arrows) and touchdowns

131 (white asterisks) are reduced in embryos with endothelial overexpression of irsp53 ${ }^{d n}$. (C-D) Cardiac trabeculation (arrowheads) is reduced in larvae with endothelial overexpression of irsp53 ${ }^{d n}$; (C'-D") 3D rendering. (E) Quantification of the number of endocardial protrusions in wild-type and in embryos with endothelial overexpression of $i r s p 53^{d n}$ at 48 hpf. (F-F') Illustration of the division of the 48 hpf ventricle into 4 regions (F). Distribution and average number of endocardial protrusions in different regions of mid-sagittal sections of the ventricle from $48 \mathrm{hpf}$ wild-type and $i r s p 53^{d n}$ embryos (F'). (G-G') Illustration of the division of the $72 \mathrm{hpf}$ ventricle into the outer and inner curvature (G). Quantification of the number of trabecular CMs in the outer curvature of wild-type and $\operatorname{irsp53^{dn}}$ larvae at $72 \mathrm{hpf}\left(\mathbf{G}^{\prime}\right)$. (H-H') $72 \mathrm{hpf}$ larvae with endothelial 

ventricle. (I) Quantification of the number of mVenus- $\mathrm{Gmnn}{ }^{+} \mathrm{CMs}$ in the ventricle of wild-type and $i r s p 53^{d n}$

141 larvae at $72 \mathrm{hpf}$. All images are ventral views, anterior to the top. V, ventricle; A, atrium. Data in graphs expressed as mean \pm SEM.

Apelin signaling positively regulates endocardial protrusion formation and myocardial trabeculation

We have recently shown that Apelin signaling regulates endothelial protrusion formation during angiogenesis in the zebrafish trunk (Helker et al., 2020). Therefore, we hypothesized that Apelin signaling might also regulate endocardial protrusion formation. To examine the expression pattern of the apelin ligand and receptor genes during heart development in zebrafish embryos, we first performed whole mount in situ hybridization. We detected apln, but no apela, expression within the heart (Figure 3-figure supplement 1A-D). For the receptor genes, we could only detect aplnrb expression in the heart (Figure 3-figure supplement 1E-H). In order to visualize the expressions of $a p / n$ and $a p / n r b$ at single cell resolution in the heart, we examined the TgBAC(apln:EGFP) reporter line (Helker et al., 2020) line and generated a novel Tg(aplnrb:VenusPEST) reporter line. We detected apln:EGFP expression in the myocardium at 48 and $72 \mathrm{hpf}$ (Figure $3 \mathrm{~A}$ and $\mathrm{B}$ ). Furthermore, we detected ap/nrb:VenusPEST expression in the endocardium at 48 and $72 \mathrm{hpf}$ (Figure $3 \mathrm{C}$ and D). These results suggest that $a p / n$ is expressed in the myocardium while aplnrb is expressed in EdCs. Based on these results, we hypothesized that Apelin signaling plays a role during endocardium-myocardium interactions. 

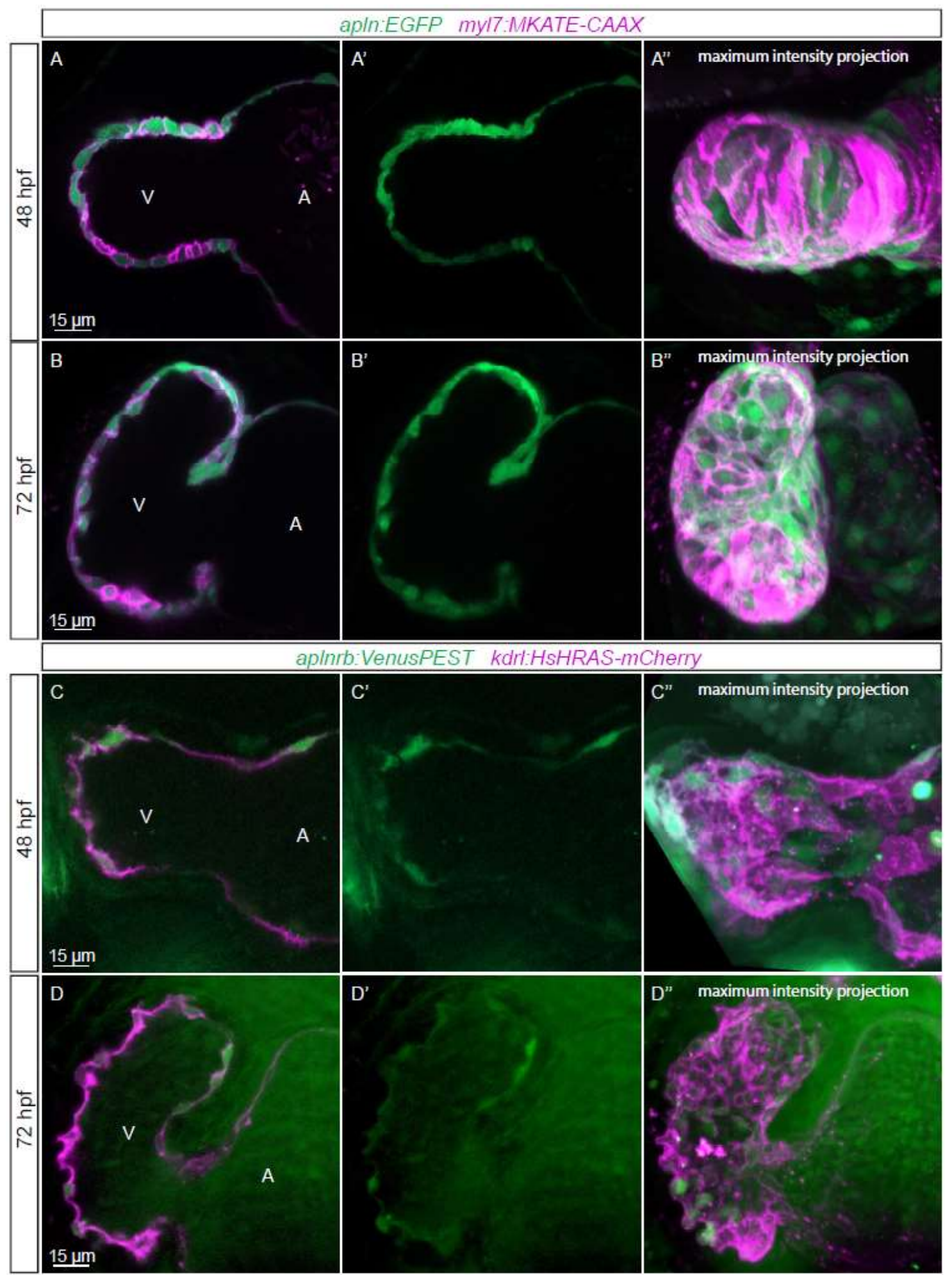

Figure 3. Expression pattern of Apelin signaling pathway components. (A-D) Confocal projection images of the heart of TgBAC(apln:EGFP); Tg(myl7:MKATE-CAAX) (A, B) and TgBAC(aplnrb:VenusPEST); Tg(kdrl:HsHRASmCherry) (C, D) zebrafish at 48 (A, C) and 72 (B, D) hpf. (A"'-D") Maximum intensity projections. (A-B) TgBAC(ap/n:EGFP) expression is detectable in the myocardium at 48 (A) and 72 (B) hpf. (C-D) TgBAC(apInrb:VenusPEST) expression is detectable in the endocardium with higher expression in the ventricular endocardium at 48 (C) and 72 (D) hpf. All images are ventral views, anterior to the top. V, ventricle; A, atrium. 
To test this hypothesis, we used mutants for aplnra (Helker et al., 2015), aplnrb (Helker et al., 2015), apln (Helker et al., 2015), and apela (Chng et al., 2013). Since apela mutants fail to form a heart (Chng et al., 2013), we did not analyze them. Most aplnrb mutants also fail to form a heart (Scott et al., 2007; Zeng et al., 2007), but some do (Figure 4-figure supplement 1C). By analyzing aplnrb mutants those do form a heart, we observed that they exhibit a reduced number of endocardial protrusions at $48 \mathrm{hpf}$ (Figure 4-figure supplement $2 \mathrm{~A}$ and $\mathrm{B}$ ) and trabeculae at $72 \mathrm{hpf}$ (Figure 4-figure supplement $2 \mathrm{C}$ and $\mathrm{D}$ ). In wild-type embryos, the $\mathrm{CJ}$ between the endocardium and myocardium in the outer curvature of the ventricle appears to be mostly degraded at $72 \mathrm{hpf}$ (Figure 4-figure supplement 2C); however, the $\mathrm{CJ}$ in aplnrb mutants appears to be thicker at this stage (Figure 4figure supplement 2D). In addition, ap/nra mutants exhibit a reduced number of trabeculae at $72 \mathrm{hpf}$ (Figure 4-figure supplement 2E and F).

While apln mutants form a heart (Figure 4-figure supplement 1F), they display a significantly lower number of endocardial protrusions at 24 and $48 \mathrm{hpf}$ (Figure 4A-D, G-I). In line with fewer endocardial protrusions, apln mutants exhibit a reduced number of endocardial touchdowns at $48 \mathrm{hpf}$ (Figure $4 \mathrm{C}$ and D). Altogether, these results indicate that Apelin signaling regulates endocardial protrusion formation.

To examine the function of Apelin dependent endocardial protrusions on cardiac trabeculation, we first analyzed trabecular formation in apln mutants. Homozygous apln mutants exhibit a reduced number of trabeculae at $72 \mathrm{hpf}$ (Figure $4 \mathrm{E}, \mathrm{F}$, and J). In order to analyze $\mathrm{CM}$ proliferation, we performed EdU labeling and quantified $\mathrm{EdU}^{+} \mathrm{CMs}$ in apln mutant and wild-type sibling larvae. Homozygous apln mutants exhibit a significantly decreased number of $\mathrm{EdU}^{+} \mathrm{CMs}$ in their ventricle (Figure 4-figure supplement 3). In addition, apln mutants display a significantly thicker CJ compared with wild-type siblings at $72 \mathrm{hpf}$ (Figure 4C-F, K, and L). However, we did not observe any obvious defects in sarcomere formation (Figure 4-figure supplement 4 ) in apln mutants at $72 \mathrm{hpf}$.

Notch signaling negatively regulates endothelial sprouting and protrusion formation in several vascular beds (Hellstrom et al., 2007; Leslie et al., 2007; Siekmann and Lawson, 2007; Suchting et al., 2007). In order to analyze whether Notch signaling also regulates endocardial protrusion formation, we blocked Notch signaling by treating embryos with the $\gamma$-secretase inhibitor RO4929097, and observed a decrease of Notch reporter expression (Figure 4-figure supplement 5A and B) as well as an increased number of endocardial protrusions in the ventricle (Figure 4-figure supplement 5C-E). Together, these results show that myocardial derived Apelin positively regulates endocardial protrusion formation while Notch signaling negatively regulates it. Furthermore, Apelin signaling is also required for cardiac trabeculation, possibly via the formation of endocardial protrusions. 


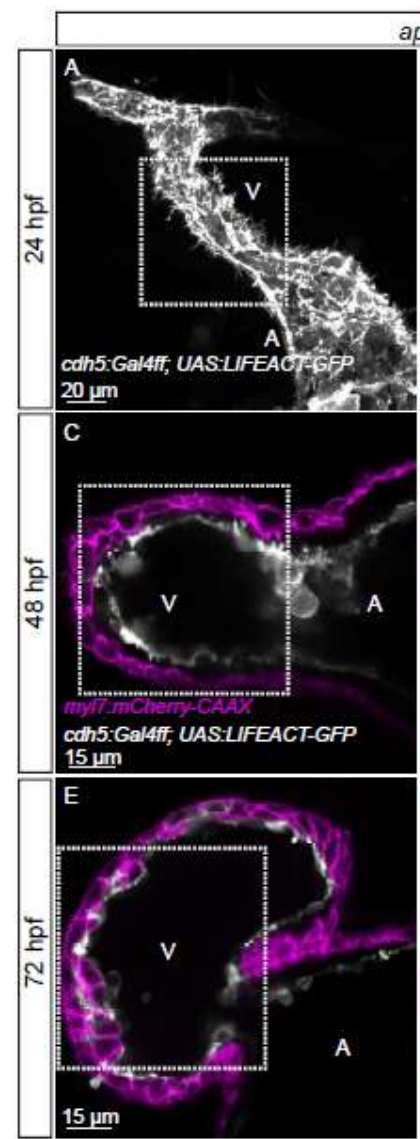

G

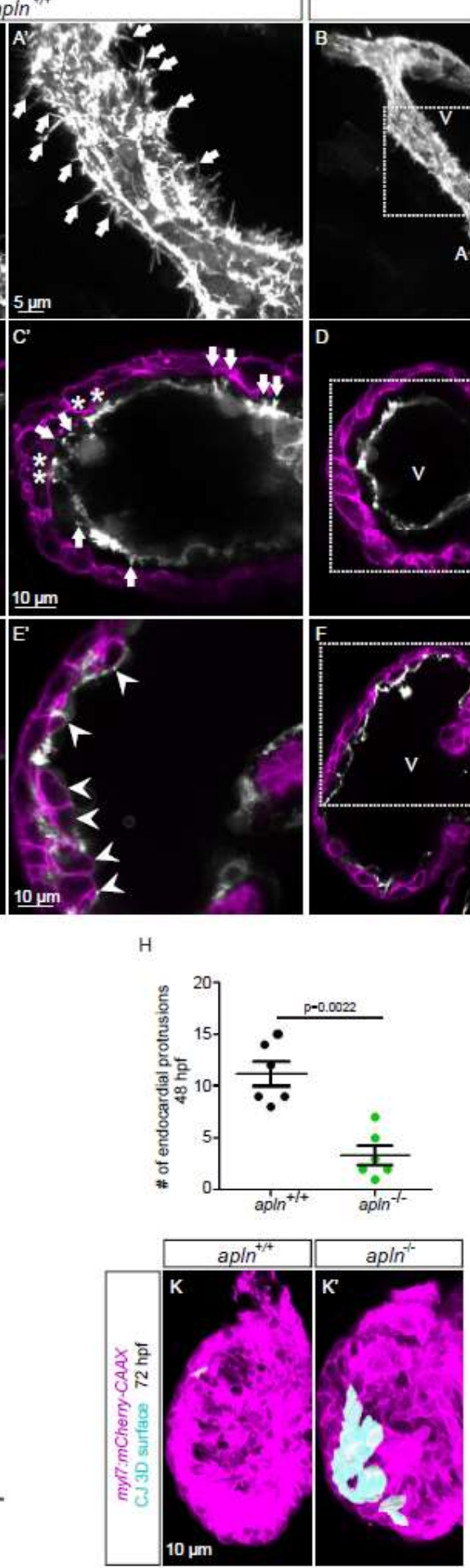

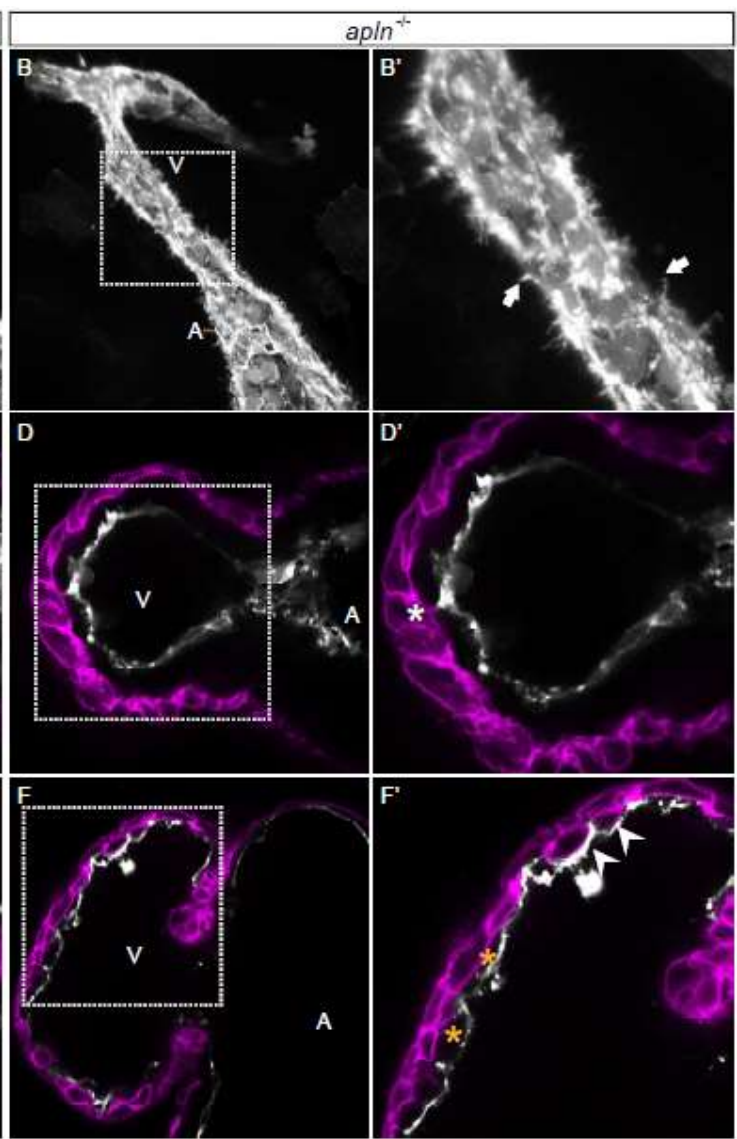

1
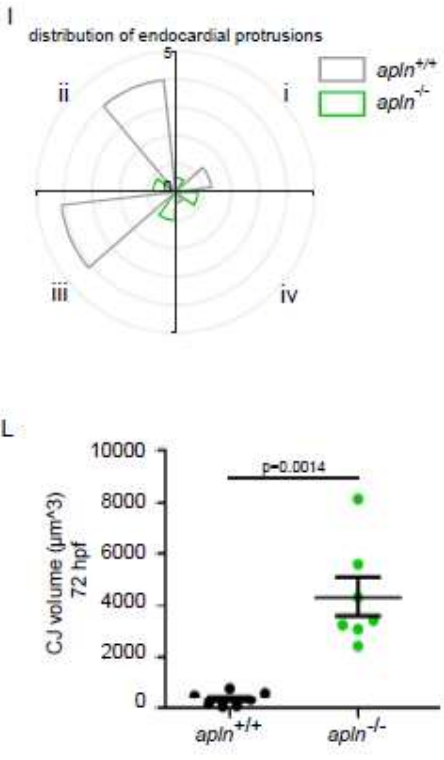

Figure 4. Loss of Apelin signaling leads to reduced endocardial protrusions and reduced myocardial

trabeculation. (A-F) Confocal projection images of the heart of $T g$ (cdh5:Gal4ff); $T g$ (UAS:LIFEACT-GFP) zebrafish at $24 \mathrm{hpf}$ (A-B) and of the heart of $\operatorname{Tg}(m y / 7: m C h e r r y-C A A X) ; T g$ (cdh5:Gal4ff); Tg(UAS:LIFEACT-GFP) (C-F) zebrafish at 48 (C-D) and 72 (E-F) hpf. Maximum intensity projections (A-B) and mid-sagittal sections (C-F). (A) Endocardial protrusions (arrows) in $a p / n^{+/+}$embryos at 24 hpf. (B) Endocardial protrusions (arrows) are reduced in $a p / h^{-\%}$ siblings at $24 \mathrm{hpf}$. (C-D) Endocardial protrusions (arrows) and touchdowns (white asterisks) are reduced in $a p / n^{-1-}$ embryos (D) at $48 \mathrm{hpf}$ compared with $a p / n^{+/+}$siblings (C). (E-F) $a p / n^{-/}$larvae (F) exhibit reduced trabeculation (arrowheads) and thicker $\mathrm{CJ}$ (yellow asterisks) at $72 \mathrm{hpf}$ compared with $a p / \mathrm{h}^{+/+}$siblings 
(E). (G-H) Quantification of the number of endocardial protrusions in the ventricle of $a p / n^{+/+}$and $a p / n^{-1}$ siblings at 24 (G) and 48 (H) hpf. (I) Distribution and average number of endocardial protrusions in different regions of mid-sagittal sections of the ventricle from $48 \mathrm{hpf} a p / n^{+/+}$and $a p / n^{-/}$siblings. (J) Quantification of the number of trabecular CMs in the outer curvature of $a p / n^{+/+}$and $a p / n^{-/}$siblings at $72 \mathrm{hpf}$. (K-K') Maximum intensity projections. ap/n ${ }^{-1}$ larvae (K') exhibit a thicker $\mathrm{CJ}$ at $72 \mathrm{hpf}$ compared with $a p / n^{+/+}$siblings (K). (L)

212 Quantification of the $\mathrm{CJ}$ volume in the outer curvature of $a p / n^{+/}$and $a p / n^{-1 /}$ siblings at $72 \mathrm{hpf}$. All images are

213 ventral views, anterior to the top. $\mathrm{V}$, ventricle; A, atrium; $+/+, a p / n^{+/+} ;-/-, a p / n^{-/}$. Data in graphs expressed as mean \pm SEM.

The effect of endocardial $n r g 2 a$ in trabeculation is mediated by endocardial protrusions

Nrg-ErbB signaling is indispensable for cardiac trabeculation in mouse and zebrafish (Gassmann et al., 1995; Lee et al., 1995; Meyer and Birchmeier, 1995; Lai et al., 2010; Liu et al., 2010; Rasouli and Stainier, 2017). To determine whether endocardial protrusions modulate Nrg-ErbB signaling, we overexpressed $n r g 2 a$ in the endocardium using a Tg(fli1a:nrg2a-p2a-tdTomato) line (Rasouli and Stainier, 2017). Overexpression of $n r g 2 a$ in the endocardium results in hypertrabeculation as well as a multilayered myocardium (Figure 5A, B, and E-G). Strikingly, overexpressing $n r g 2 a$ in the endothelium while blocking endocardial protrusion formation by endothelial overexpression of $\operatorname{irsp} 53^{d n}$ is not sufficient to restore cardiac trabeculation and induce CM multilayering (Figure $5 \mathrm{C}-\mathrm{C}^{\prime \prime \prime}$ and $\mathrm{E}-\mathrm{G})$. In line with these results, overexpressing $n r g 2 a$ in the endothelium of homozygous ap/n mutants is not sufficient to restore cardiac trabeculation and induce CM multilayering (Figure 5D-D"' and E-G). Importantly, we did not detect a change in the expression levels of $n r g 2 a$ in apln mutant hearts at $48 \mathrm{hpf}$ (Figure 5-figure supplement 1). Taken together, these data suggest that endocardial protrusions are required for $\mathrm{Nrg}$-ErbB signaling. 



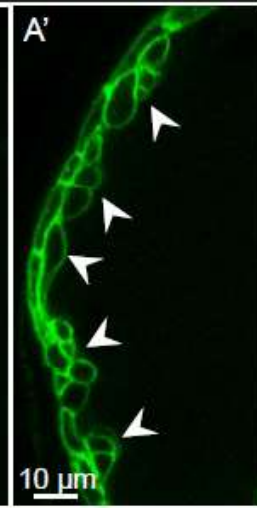

mato
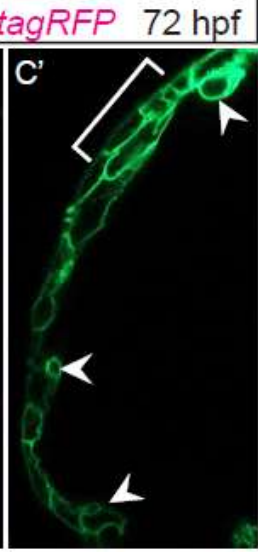

F

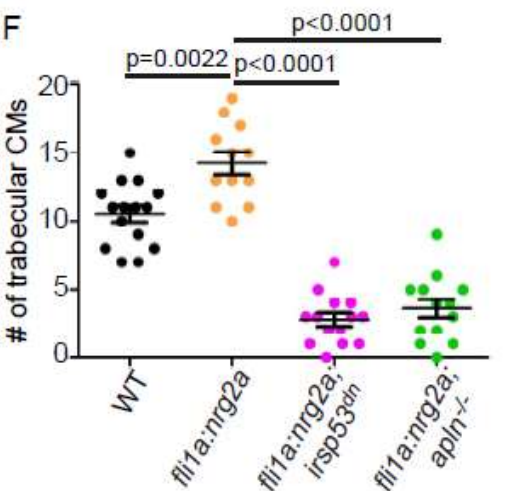

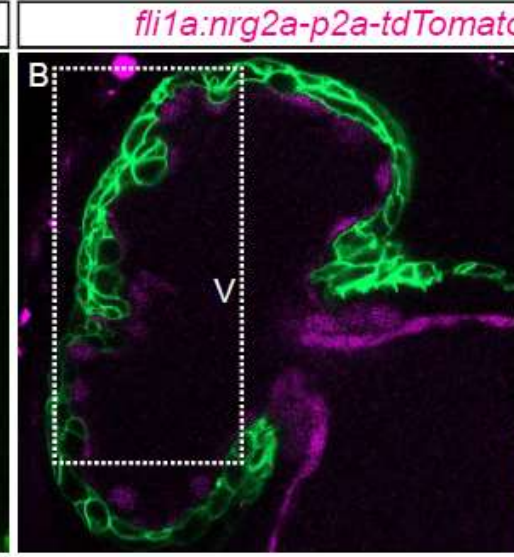

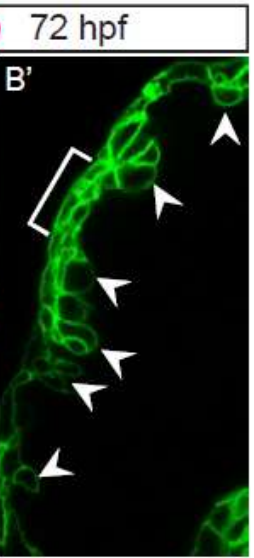

fli1a:nrg2a-p2a-tdTomato ap/n ${ }^{-1-} 72 \mathrm{hpf}$


Figure 5. Endocardial protrusions are necessary for $n$ rg2a overexpression phenotypes. (A-D) Confocal projection images of the heart of $T g$ (myl7:HsHRAS-EGFP) larvae at $72 \mathrm{hpf}$. (A-B) Overexpression of $n r g 2 a$ in the endothelium (B) leads to an increased number of trabeculae (arrowheads) and the multilayering of CMs (brackets) compared with wild-type (A). (C) Larvae with endothelial overexpression of $n r g 2 a$ and $i r s p 53^{d n}$ exhibit a reduced number of trabeculae (arrowheads) and of multilayered CMs (brackets) compared with larvae with endothelial overexpression of $n r g 2 a$ alone (B).

(B). (D) ap/n mutant larvae with endothelial overexpression of nrg2a exhibit a reduced number of trabeculae (arrowheads) and of multilayered CMs (brackets) compared with larvae with endothelial overexpression of $n r g 2 a$ alone (B). (E) Quantification of the number of trabeculae. (F) Quantification of the number of trabecular CMs.

(G) Quantification of the number of multilayered CMs in the ventricle. Brackets indicate multilayered CMs. All images are ventral views, anterior to the top. $V$, ventricle. Data in graphs expressed as mean \pm SEM. 
241 An important molecule in the $\mathrm{Nrg} / \mathrm{ErbB}$ signaling pathway is the extracellular signal-regulated kinase

242 Erk (Lai et al., 2010). In order to visualize Erk activity in CMs in living zebrafish, as a readout of ErbB

243 signaling, we generated novel reporter lines (Tg(my/7:ERK-KTR-Clover-p2a-H2B-tagBFP) and

$244 T g(m y / 7: E R K-K T R$-Clover-p2a-H2B-mScarlet)) by using the kinase translocation reporter (KTR)

245 technology (Regot et al., 2014; de la Cova et al., 2017). When Erk is inactive, the KTR is

246 unphosphorylated and Clover can be detected in the nucleus; in contrast, when Erk is active, the KTR

247 is phosphorylated and Clover can be detected in the cytoplasm (de la Cova et al., 2017). We

248 observed that most ventricular CMs in wild-type larvae display active Erk signaling with cytoplasmic

249 Clover expression (Figure 6A). Treating the reporter with a MEK inhibitor led to an increased number

250 of ventricular CMs with nuclear Clover expression (i.e., inactive Erk signaling) indicating that our

251 reporter is functional (Figure 6-figure supplement 1 ). Next, we treated this reporter with an ErbB2

252 inhibitor and found an increased number of ventricular CMs with nuclear Clover expression (Figure

253 6B). To determine whether endocardial protrusions modulate myocardial Erk signaling activity, we

254 genetically blocked endocardial protrusions via endothelial overexpression of irsp $53^{d n}$ (Figure 6C).

255 We observed more ventricular CMs with nuclear Clover expression in the larvae overexpressing

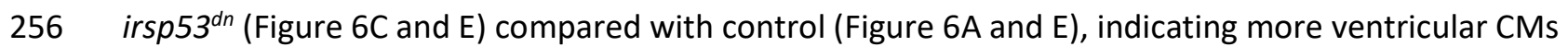

257 with inactive Erk signaling. In line with these results, we observed more CMs with inactive Erk

258 signaling in homozygous apln mutants (Figure 6D and E) compared with wild-type siblings (Figure 6A

259 and E). Altogether, these observations indicate that Apelin signaling dependent endocardial protrusions modulate $\mathrm{Nrg} / \mathrm{ErbB} /$ Erk signaling in $\mathrm{CMs}$. 



Figure 6. Blocking endocardial protrusion formation reduces myocardial Erk signaling activity. (A-D)

Maximum intensity projections of confocal images of the heart of Tg(myl7:ERK-KTR-Clover-p2a-H2BClover expression (arrows) indicates CMs with inactive Erk signaling. (B) Larvae treated with an ErbB2 inhibitor exhibit an increased number of CMs with inactive Erk signaling (arrows) compared with control larvae (A). (C) 
signaling (arrows) compared with wild-type larvae (A). (D) apln mutant larvae exhibit an increased number of CMs with inactive Erk signaling (arrows) compared with $a p / n^{+/+}$siblings. (E) Quantification of ventricular CMs with nuclear Clover expression. All images are ventral views, anterior to the top. $V$, ventricle. Data in graphs expressed as mean \pm SEM.

\section{Discussion}

\section{Endocardial protrusions contribute to trabeculation}

273 Cardiac trabeculation is initiated, at least in zebrafish, by individual CMs delaminating from the compact myocardial wall and protruding into the lumen (Liu et al., 2010; Staudt et al., 2014; JimenezAmilburu et al., 2016; Priya et al., 2020). Several studies have reported that the endocardium plays an important role during cardiac trabeculation (Grego-Bessa et al., 2007; Lai et al., 2010; D'Amato et al., 2016; Rasouli and Stainier, 2017; Del Monte-Nieto et al., 2018; Qu et al., 2019). Furthermore, it has recently been shown that EdCs, similar to ECs, undergo sprouting (Del Monte-Nieto et al., 2018). However, in comparison with endocardial sprouting, little is known about the morphogenetic events underlying endocardial sprouting and their effect on cardiac trabeculation.

In mouse, endocardial sprouting and touchdown formation occur early during cardiac trabeculation (Del Monte-Nieto et al., 2018). These observations are in line with our data in zebrafish suggesting that the morphogenetic events of cardiac trabeculation are evolutionarily conserved. CM delamination and trabeculation occur in the outer curvature of the ventricle (Liu et al., 2010; Jimenez-Amilburu et al., 2016; Rasouli and Stainier, 2017). This observation is in line with our finding that endocardial protrusions are mostly located in the outer curvature of the ventricle. The spatial and temporal correlation between the emergence of endocardial protrusions and CM delamination therefore suggests a role for endocardial protrusions in cardiac trabeculation.

\section{Molecular regulators of endocardial sprouting}

290 During sprouting angiogenesis, so-called tip cells lead the new sprouts (Gerhardt, 2008). Tip cells 291 dynamically extend filopodia to identify growth factors in their environment (Gerhardt, 2008). Apelin 292 and Notch signaling have been previously identified as regulators of endothelial filopodia formation 293 (Hellstrom et al., 2007; Suchting et al., 2007; Helker et al., 2020). In contrast, the pathways 294 regulating endocardial sprouting are largely unknown. Only Tie2 signaling has been identified to date as a regulator of endocardial sprouting, and Tie2 deficient mice exhibit fewer endocardial touchdowns (Qu et al., 2019). We have recently shown that Apelin signaling regulates filopodia formation during sprouting angiogenesis in the trunk (Helker et al., 2020). In line with these published observations, we now show that Apelin regulates endocardial filopodia formation and 
endocardial sprouting (Figure 6-figure supplement 2), highlighting a conserved role for Apelin signaling during endothelial and endocardial sprouting.

Consistent with the regulation of sprouting angiogenesis by Notch signaling in ECs (Hellstrom et al., 2007; Leslie et al., 2007; Siekmann and Lawson, 2007; Suchting et al., 2007), we found that Notch signaling also negatively regulates endocardial protrusion formation. Interestingly, inhibition of Notch signaling also leads to an increased number of delaminated CMs and trabeculae (Han et al., 2016; Priya et al., 2020).

\section{Endocardium-myocardium communication is essential for trabeculation}

Paracrine communication is usually thought to be based on the diffusion of soluble morphogens. The $\mathrm{Nrg} /$ ErbB signaling pathway, which is required for cardiac trabeculation, resembles such a classical paracrine signaling pathway (Gassmann et al., 1995; Lee et al., 1995; Meyer and Birchmeier, 1995; Lai et al., 2010; Liu et al., 2010; Rasouli and Stainier, 2017). Several studies have shown that endocardial derived $\mathrm{Nrg}$ is required to activate ErbB receptor complexes on CMs (Gassmann et al., 1995; Meyer and Birchmeier, 1995; Grego-Bessa et al., 2007; Rasouli and Stainier, 2017).

Like other receptor tyrosine kinases, ErbB receptors activate multiple signaling cascades, including the MAPK cascade, upon ligand stimulation, leading to the phosphorylation of ERK1/2 (Sweeney et al., 2001; Wee and Wang, 2017). Accordingly, attenuated phosphorylation of ERK in CMs is observed in mice deficient in Nrg1/ErbB signaling (Lai et al., 2010). By analyzing a novel reporter of Erk activity in CMs, we observed that the inhibition of endocardial protrusions as well as the genetic inactivation of Apelin signaling lead to attenuated Erk phosphorylation in CMs. Together, these data suggest that Apelin signaling dependent endocardial protrusions modulate ErbB signaling in CMs (Figure 6-figure supplement 2).

It has recently been shown that filopodia from ECs modulate neurogenesis by affecting progenitor cell proliferation in the developing brain of mice and zebrafish (Di Marco et al., 2020; Taberner et al., 2020). Of interest, ErbB signaling is also known for its function within the nervous system (Buonanno and Fischbach, 2001). Thus, one might speculate that $\mathrm{Nrg} / \mathrm{ErbB}$ signaling also plays a role during the modulation of neurogenesis by endothelial filopodia. Several studies reported cell to cell communication by cytonemes in different animal models (Ramirez-Weber and Kornberg, 1999; Holzer et al., 2012; Luz et al., 2014; Sagar et al., 2015). Whether endocardial protrusions qualify as cytonemes needs further analysis. However, our data indicate that Apelin dependent endocardial protrusions are required for the communication between endocardial and myocardial cells via $\mathrm{Nrg} /$ ErbB signaling (Figure 6-figure supplement 2). 
In summary, our work describes how endocardial sprouting is integrated into $\mathrm{Nrg} / \mathrm{ErbB}$ signaling and cardiac trabeculation. Furthermore, we identify Apelin signaling as a regulator of endocardial sprouting.

\section{Acknowledgements}

We thank Gisela Thana Hartmann, Sarah Howard, Dr. Radhan Ramadass, and all fish facility staff for their technical support; Dr. Thomas Juan, Dr. Samuel Capon, Dr. Jordan Welker, Giulia Boezio and Yiu Chun Law for critical comments on the manuscript; Dr. Stefan Baumeister for the schematic model; and Dr. Gonzalo del Monte-Nieto for discussion. Research in the Stainier laboratory is supported in part by the Max Planck Society, the DFG (SFB 834/4) and the Leducq Foundation. Research in the Helker laboratory is supported in part by the DFG (SFB 834/4).

\section{Author contributions}

J.Q., D.Y.R.S. and C.S.M.H. designed experiments, J.Q. and A.R. performed experiments, A.R., R.P., S.M. provided unpublished transgenic lines, J.Q., D.Y.R.S., C.S.M.H. analyzed data, J.Q., D.Y.R.S., and C.S.M.H. wrote the manuscript. All authors commented on the manuscript.

\section{Author information}

The authors declare no competing interests.

\section{Supplemental videos}

Figure 1-video 1. Endocardial touchdowns during cardiac contraction. Related to figure 1E-1H.

Beating 48 hpf zebrafish heart. Magenta, myocardium; white, endocardium.

Figure 1-video 2. Endocardial protrusions extend along delaminating CMs at $60 \mathrm{hpf}$. Related to figure $1 C^{\prime \prime \prime}$.

3D surface rendering of a $60 \mathrm{hpf}$ ventricle. Magenta, myocardium; white, endocardium; yellow, endocardial protrusions extending along delaminating CMs.

Figure 1-video 3. Endocardial protrusions are in close proximity to trabecular CMs at $72 \mathbf{~ h p f . ~}$

\section{Related to figure 1D'"'.}

3D surface rendering of a $72 \mathrm{hpf}$ ventricle. Magenta, myocardium; white, endocardium; yellow, endocardial protrusions in close proximity to trabecular CMs.

\section{References}


STAINIER, D. Y. \& FISHMAN, M. C. 1992. Patterning the zebrafish heart tube: acquisition of anteroposterior polarity. Dev Biol, 153, 91-101.

GASSMANN, M., CASAGRANDA, F., ORIOLI, D., SIMON, H., LAI, C., KLEIN, R. \& LEMKE, G. 1995. Aberrant neural and cardiac development in mice lacking the ErbB4 neuregulin receptor. Nature, 378, 390-4.

LEE, K. F., SIMON, H., CHEN, H., BATES, B., HUNG, M. C. \& HAUSER, C. 1995. Requirement for neuregulin receptor erbB2 in neural and cardiac development. Nature, 378, 394-8.

MEYER, D. \& BIRCHMEIER, C. 1995. Multiple essential functions of neuregulin in development. Nature, 378, 386-90.

SURI, C., JONES, P. F., PATAN, S., BARTUNKOVA, S., MAISONPIERRE, P. C., DAVIS, S., SATO, T. N. \& YANCOPOULOS, G. D. 1996. Requisite role of angiopoietin-1, a ligand for the TIE2 receptor, during embryonic angiogenesis. Cell, 87, 1171-80.

SEDMERA, D. \& THOMAS, P. S. 1996. Trabeculation in the embryonic heart. Bioessays, 18, 607.

BRUTSAERT, D. L., DE KEULENAER, G. W., FRANSEN, P., MOHAN, P., KALUZA, G. L., ANDRIES, L. J., ROULEAU, J. L. \& SYS, S. U. 1996. The cardiac endothelium: functional morphology, development, and physiology. Prog Cardiovasc Dis, 39, 239-62.

RAMIREZ-WEBER, F. A. \& KORNBERG, T. B. 1999. Cytonemes: Cellular processes that project to the principal signaling center in Drosophila imaginal discs. Cell, 97, 599-607.

SEDMERA, D., PEXIEDER, T., VUILLEMIN, M., THOMPSON, R. P. \& ANDERSON, R. H. 2000. Developmental patterning of the myocardium. Anat Rec, 258, 319-37.

OECHSLIN, E. N., ATTENHOFER JOST, C. H., ROJAS, J. R., KAUFMANN, P. A. \& JENNI, R. 2000. Longterm follow-up of 34 adults with isolated left ventricular noncompaction: a distinct cardiomyopathy with poor prognosis. J Am Coll Cardiol, 36, 493-500.

BUONANNO, A. \& FISCHBACH, G. D. 2001. Neuregulin and ErbB receptor signaling pathways in the nervous system. Curr Opin Neurobiol, 11, 287-96.

SWEENEY, C., FAMBROUGH, D., HUARD, C., DIAMONTI, A. J., LANDER, E. S., CANTLEY, L. C. \& CARRAWAY, K. L., 3RD 2001. Growth factor-specific signaling pathway stimulation and gene expression mediated by ErbB receptors. J Biol Chem, 276, 22685-98.

NAKAGAWA, H., MIKI, H., NOZUMI, M., TAKENAWA, T., MIYAMOTO, S., WEHLAND, J. \& SMALL, J. V. 2003. IRSp53 is colocalised with WAVE2 at the tips of protruding lamellipodia and filopodia independently of Mena. Journal of Cell Science, 116, 2577-2583.

GERHARDT, H., GOLDING, M., FRUTTIGER, M., RUHRBERG, C., LUNDKVIST, A., ABRAMSSON, A., JELTSCH, M., MITCHELL, C., ALITALO, K., SHIMA, D. \& BETSHOLTZ, C. 2003. VEGF guides angiogenic sprouting utilizing endothelial tip cell filopodia. J Cell Biol, 161, 1163-77.

CLAUDIA, S. \& JOSEF, F. 2004. Left ventricular hypertrabeculation/noncompaction. Journal of the American Society of Echocardiography, 17, 91-100.

TACHIBANA, K., JONES, N., DUMONT, D. J., PURI, M. C. \& BERNSTEIN, A. 2005. Selective role of a distinct tyrosine residue on Tie2 in heart development and early hematopoiesis. Mol Cell Biol, $25,4693-702$.

MILLARD, T. H., BOMPARD, G., HEUNG, M. Y., DAFFORN, T. R., SCOTT, D. J., MACHESKY, L. M. \& FUTTERER, K. 2005. Structural basis of filopodia formation induced by the IRSp53/MIM homology domain of human IRSp53. EMBO J, 24, 240-50.

SUCHTING, S., FREITAS, C., LE NOBLE, F., BENEDITO, R., BREANT, C., DUARTE, A. \& EICHMANN, A. 2007. The Notch ligand Delta-like 4 negatively regulates endothelial tip cell formation and vessel branching. Proc Natl Acad Sci U S A, 104, 3225-30.

HELLSTROM, M., PHNG, L. K., HOFMANN, J. J., WALLGARD, E., COULTAS, L., LINDBLOM, P., ALVA, J., NILSSON, A. K., KARLSSON, L., GAIANO, N., YOON, K., ROSSANT, J., IRUELA-ARISPE, M. L., KALEN, M., GERHARDT, H. \& BETSHOLTZ, C. 2007. DII4 signalling through Notch1 regulates formation of tip cells during angiogenesis. Nature, 445, 776-780.

GREGO-BESSA, J., LUNA-ZURITA, L., DEL MONTE, G., BOLOS, V., MELGAR, P., ARANDILLA, A., GARRATT, A. N., ZANG, H., MUKOUYAMA, Y. S., CHEN, H. Y., SHOU, W. N., BALLESTAR, E., 
ESTELLER, M., ROJAS, A., PEREZ-POMARES, J. M. \& DE LA POMPA, J. L. 2007. Notch signaling is essential for ventricular chamber development. Developmental Cell, 12, 415-429.

LESLIE, J. D., ARIZA-MCNAUGHTON, L., BERMANGE, A. L., MCADOW, R., JOHNSON, S. L. \& LEWIS, J. 2007. Endothelial signalling by the Notch ligand Delta-like 4 restricts angiogenesis. Development, 134, 839-44.

SIEKMANN, A. F. \& LAWSON, N. D. 2007. Notch signalling limits angiogenic cell behaviour in developing zebrafish arteries. Nature, 445, 781-4.

STANKUNAS, K., HANG, C. T., TSUN, Z. Y., CHEN, H., LEE, N. V., WU, J. I., SHANG, C., BAYLE, J. H., SHOU, W., IRUELA-ARISPE, M. L. \& CHANG, C. P. 2008. Endocardial Brg1 represses ADAMTS1 to maintain the microenvironment for myocardial morphogenesis. Dev Cell, 14, 298-311.

SCITA, G., CONFALONIERI, S., LAPPALAINEN, P. \& SUETSUGU, S. 2008. IRSp53: crossing the road of membrane and actin dynamics in the formation of membrane protrusions. Trends Cell Biol, $18,52-60$.

GERHARDT, H. 2008. VEGF and endothelial guidance in angiogenic sprouting. Organogenesis, 4, 2416.

LIU, J., BRESSAN, M., HASSEL, D., HUISKEN, J., STAUDT, D., KIKUCHI, K., POSS, K. D., MIKAWA, T. \& STAINIER, D. Y. 2010. A dual role for ErbB2 signaling in cardiac trabeculation. Development, $137,3867-75$.

LAI, D., LIU, X. F., FORRAI, A., WOLSTEIN, O., MICHALICEK, J., AHMED, I., GARRATT, A. N., BIRCHMEIER, C., ZHOU, M., HARTLEY, L., ROBB, L., FENELEY, M. P., FATKIN, D. \& HARVEY, R. P. 2010. Neuregulin 1 Sustains the Gene Regulatory Network in Both Trabecular and Nontrabecular Myocardium. Circulation Research, 107, 715-U74.

PESHKOVSKY, C., TOTONG, R. \& YELON, D. 2011. Dependence of cardiac trabeculation on neuregulin signaling and blood flow in zebrafish. Dev Dyn, 240, 446-56.

ROY, S., HSIUNG, F. \& KORNBERG, T. B. 2011. Specificity of Drosophila cytonemes for distinct signaling pathways. Science, 332, 354-8.

HOLZER, T., LIFFERS, K., RAHM, K., TRAGESER, B., OZBEK, S. \& GRADL, D. 2012. Live imaging of active fluorophore labelled Wnt proteins. FEBS Lett, 586, 1638-44.

SANDERS, T. A., LLAGOSTERA, E. \& BARNA, M. 2013. Specialized filopodia direct long-range transport of SHH during vertebrate tissue patterning. Nature, 497, 628-32.

CHNG, S. C., HO, L., TIAN, J. \& REVERSADE, B. 2013. ELABELA: a hormone essential for heart development signals via the apelin receptor. Dev Cell, 27, 672-80.

FIERRO-GONZALEZ, J. C., WHITE, M. D., SILVA, J. C. \& PLACHTA, N. 2013. Cadherin-dependent filopodia control preimplantation embryo compaction. Nat Cell Biol, 15, 1424-33.

STAUDT, D. W., LIU, J., THORN, K. S., STUURMAN, N., LIEBLING, M. \& STAINIER, D. Y. 2014. Highresolution imaging of cardiomyocyte behavior reveals two distinct steps in ventricular trabeculation. Development, 141, 585-93.

REGOT, S., HUGHEY, J. J., BAJAR, B. T., CARRASCO, S. \& COVERT, M. W. 2014. High-sensitivity measurements of multiple kinase activities in live single cells. Cell, 157, 1724-34.

LUZ, M., SPANNL-MULLER, S., OZHAN, G., KAGERMEIER-SCHENK, B., RHINN, M., WEIDINGER, G. \& BRAND, M. 2014. Dynamic association with donor cell filopodia and lipid-modification are essential features of Wnt8a during patterning of the zebrafish neuroectoderm. PLoS One, 9, e84922.

HELKER, C. S., SCHUERMANN, A., POLLMANN, C., CHNG, S. C., KIEFER, F., REVERSADE, B. \& HERZOG, W. 2015. The hormonal peptide Elabela guides angioblasts to the midline during vasculogenesis. Elife, 4.

StANGANELlO, E., HAGEMANN, A. I., MATTES, B., SINNER, C., MEYEN, D., WEBER, S., SCHUG, A., RAZ, E. \& SCHOLPP, S. 2015. Filopodia-based Wnt transport during vertebrate tissue patterning. Nat Commun, 6, 5846.

SAGAR, PROLS, F., WIEGREFFE, C. \& SCAAL, M. 2015. Communication between distant epithelial cells by filopodia-like protrusions during embryonic development. Development, 142, 665-671. 
D'AMATO, G., LUXAN, G., DEL MONTE-NIETO, G., MARTINEZ-POVEDA, B., TORROJA, C., WALTER, W., BOCHTER, M. S., BENEDITO, R., COLE, S., MARTINEZ, F., HADJANTONAKIS, A. K., UEMURA, A., JIMENEZ-BORREGUERO, L. J. \& DE LA POMPA, J. L. 2016. Sequential Notch activation regulates ventricular chamber development. Nat Cell Biol, 18, 7-20.

JIMENEZ-AMILBURU, V., RASOULI, S. J., STAUDT, D. W., NAKAJIMA, H., CHIBA, A., MOCHIZUKI, N. \& STAINIER, D. Y. R. 2016. In Vivo Visualization of Cardiomyocyte Apicobasal Polarity Reveals Epithelial to Mesenchymal-like Transition during Cardiac Trabeculation. Cell Rep, 17, 26872699.

HAN, P., BLOOMEKATZ, J., REN, J., ZHANG, R., GRINSTEIN, J. D., ZHAO, L., BURNS, C. G., BURNS, C. E., ANDERSON, R. M. \& CHI, N. C. 2016. Coordinating cardiomyocyte interactions to direct ventricular chamber morphogenesis. Nature, 534, 700-4.

RASOULI, S. J. \& STAINIER, D. Y. R. 2017. Regulation of cardiomyocyte behavior in zebrafish trabeculation by Neuregulin 2a signaling. Nat Commun, 8, 15281.

ROTTNER, K., FAIX, J., BOGDAN, S., LINDER, S. \& KERKHOFF, E. 2017. Actin assembly mechanisms at a glance. Journal of Cell Science, 130, 3427-3435.

DE LA COVA, C., TOWNLEY, R., REGOT, S. \& GREENWALD, I. 2017. A Real-Time Biosensor for ERK Activity Reveals Signaling Dynamics during C. elegans Cell Fate Specification. Dev Cell, 42, 542-553 e4.

WEE, P. \& WANG, Z. 2017. Epidermal Growth Factor Receptor Cell Proliferation Signaling Pathways. Cancers (Basel), 9.

DEL MONTE-NIETO, G., RAMIALISON, M., ADAM, A. A. S., WU, B., AHARONOV, A., D'UVA, G., BOURKE, L. M., PITULESCU, M. E., CHEN, H., DE LA POMPA, J. L., SHOU, W., ADAMS, R. H., HARTEN, S. K., TZAHOR, E., ZHOU, B. \& HARVEY, R. P. 2018. Control of cardiac jelly dynamics by NOTCH1 and NRG1 defines the building plan for trabeculation. Nature, 557, 439-445.

SANDIREDDY, R., CIBI, D. M., GUPTA, P., SINGH, A., TEE, N., UEMURA, A., EPSTEIN, J. A. \& SINGH, M. K. 2019. Semaphorin 3E/PlexinD1 signaling is required for cardiac ventricular compaction. Jci Insight, 4.

QU, X., HARMELINK, C. \& BALDWIN, H. S. 2019. Tie2 regulates endocardial sprouting and myocardial trabeculation. JCl Insight, 5.

HUANG, H., LIU, S. M. \& KORNBERG, T. B. 2019. Glutamate signaling at cytoneme synapses. Science, $363,948-+$.

DI MARCO, B., CROUCH, E. E., SHAH, B., DUMAN, C., PAREDES, M. F., DE ALMODOVAR, C. R., HUANG, E. J. \& ALFONSO, J. 2020. Reciprocal Interaction between Vascular Filopodia and Neural Stem Cells Shapes Neurogenesis in the Ventral Telencephalon. Cell Reports, 33.

HELKER, C. S., EBERLEIN, J., WILHELM, K., SUGINO, T., MALCHOW, J., SCHUERMANN, A., BAUMEISTER, S., KWON, H. B., MAISCHEIN, H. M., POTENTE, M., HERZOG, W. \& STAINIER, D. Y. 2020. Apelin signaling drives vascular endothelial cells toward a pro-angiogenic state. Elife, 9.

PRIYA, R., ALLANKI, S., GENTILE, A., MANSINGH, S., URIBE, V., MAISCHEIN, H. M. \& STAINIER, D. Y. R. 2020. Tension heterogeneity directs form and fate to pattern the myocardial wall. Nature, 588, 130-134.

TABERNER, L., BANON, A. \& ALSINA, B. 2020. Sensory Neuroblast Quiescence Depends on Vascular Cytoneme Contacts and Sensory Neuronal Differentiation Requires Initiation of Blood Flow. Cell Rep, 32, 107903. 
A

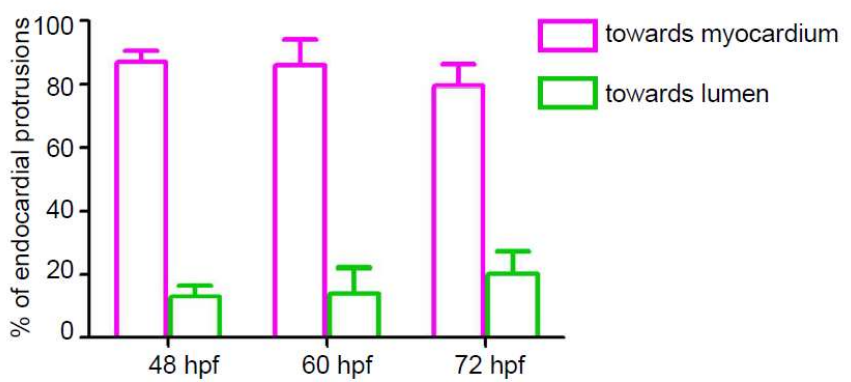

B

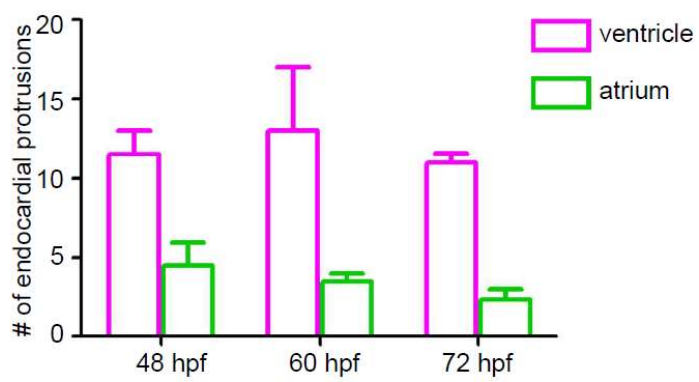

Figure 1-figure supplement 1. Endocardial protrusions in the ventricle extend mainly towards the

506 myocardium. (A) Quantification of the direction of endocardial protrusions; most endocardial protrusions extend towards the myocardium. (B) Quantification of the average number of endocardial protrusions in the ventricle and atrium. $n=9$ in each group. 

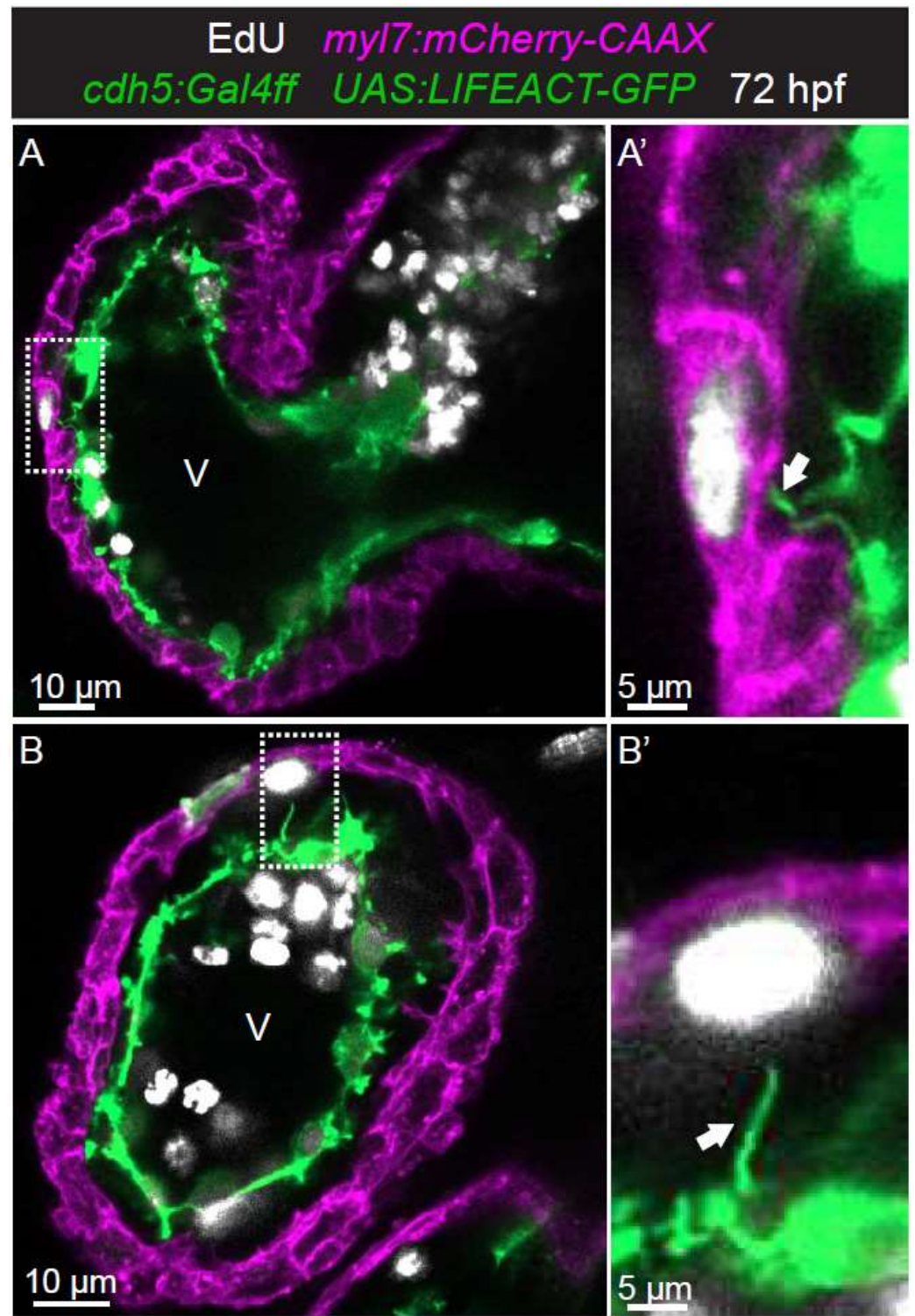

509 Figure 1-figure supplement 2. Endocardial protrusions most often contact proliferating CMs. (A-B) Confocal

510 projection images of $72 \mathrm{hpf} T g$ (myl7:mCherry-CAAX); $T g$ (cdh5:Gal4ff); Tg(UAS:LIFEACT-GFP) hearts after EdU

511 labeling from 28 to 72 hpf. ( $\left.A^{\prime}-B^{\prime}\right)$ Arrows point to endocardial protrusions close to EdU ${ }^{+} C M s(n=8)$. All images are ventral views, anterior to the top. $\mathrm{V}$, ventricle. 


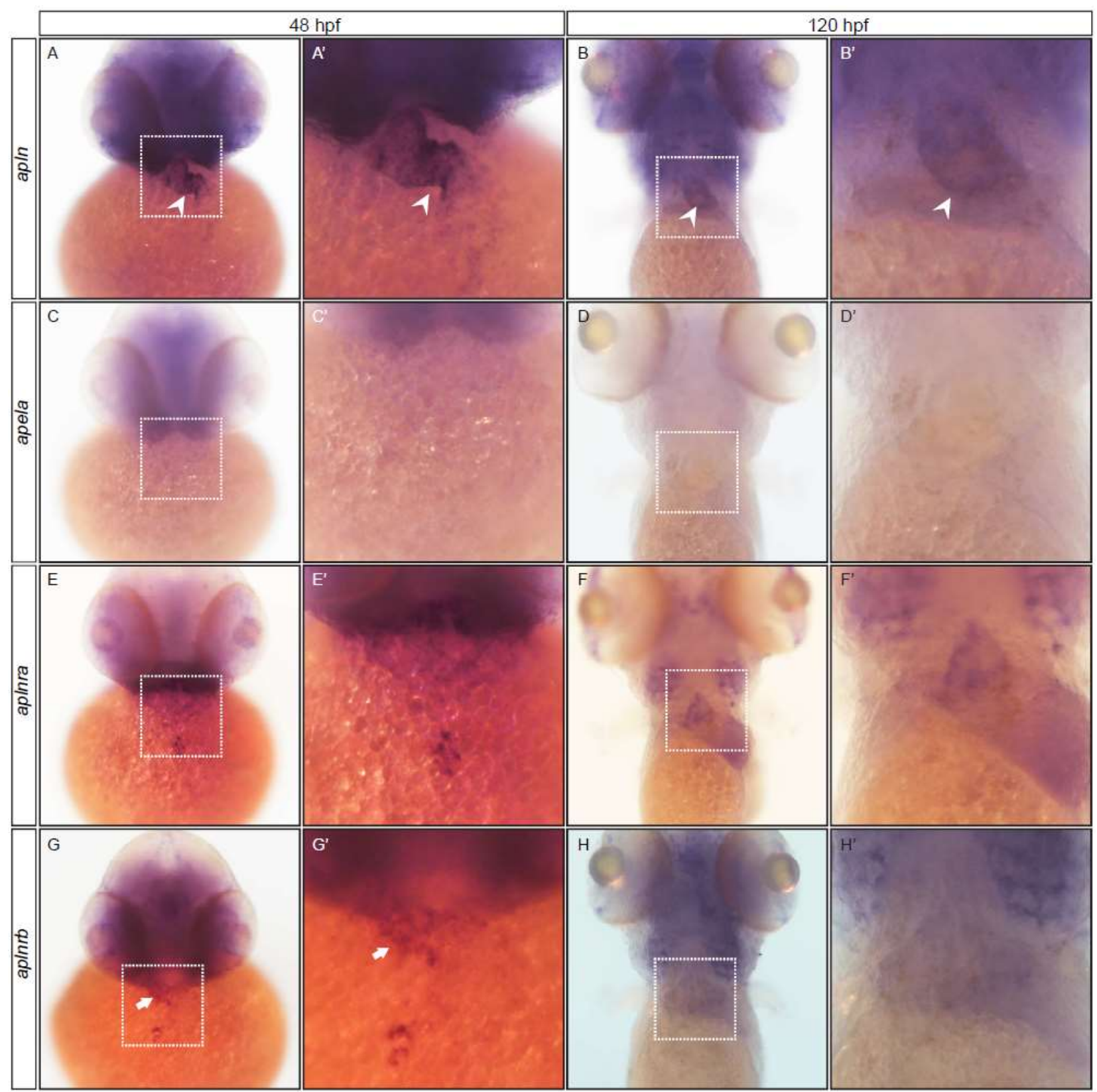

513 Figure 3-figure supplement 1. Expression of Apelin signaling ligand and receptor genes by in situ

514 hybridization. (A-H) Expression of Apelin signaling ligand and receptor genes at 48 and $120 \mathrm{hpf}$. (A-B) ap/n is

515 expressed in the developing heart (arrowheads). (C-D) apela expression is not detected in the developing

516 heart. (E-F) ap/nra expression is not detected in the developing heart. (G-H) ap/nrb is expressed in the

517 developing heart (arrows). White box, heart region. 


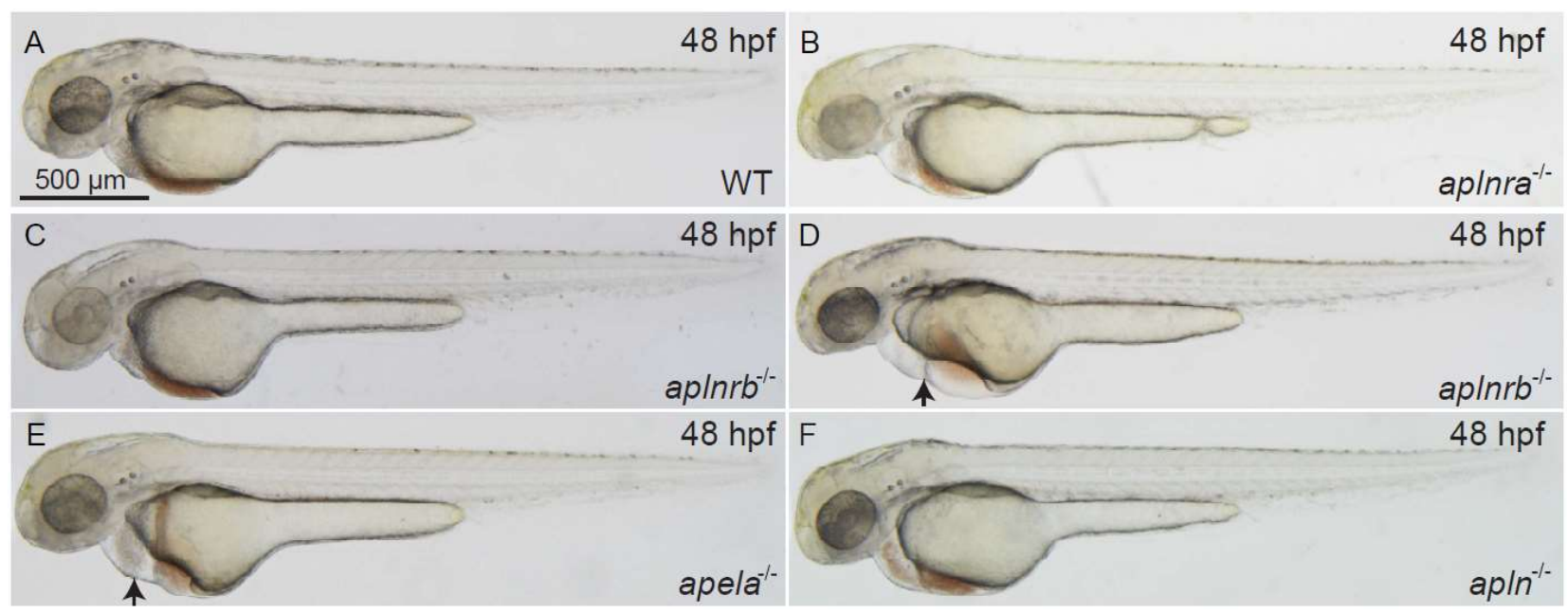

518 Figure 4-figure supplement 1. Bright field pictures of ap/nra, aplnrb, apela and apln mutants. (A-F)

519 Brightfield pictures (lateral views) of $48 \mathrm{hpf}$ wild-type (A), ap/nra mutant (B), ap/nrb mutant without pericardial

520 edema (C), aplnrb mutant with pericardial edema (arrow) (D), apela mutant with pericardial edema (arrow) (E),

521 and ap/n mutant without pericardial edema (F). 


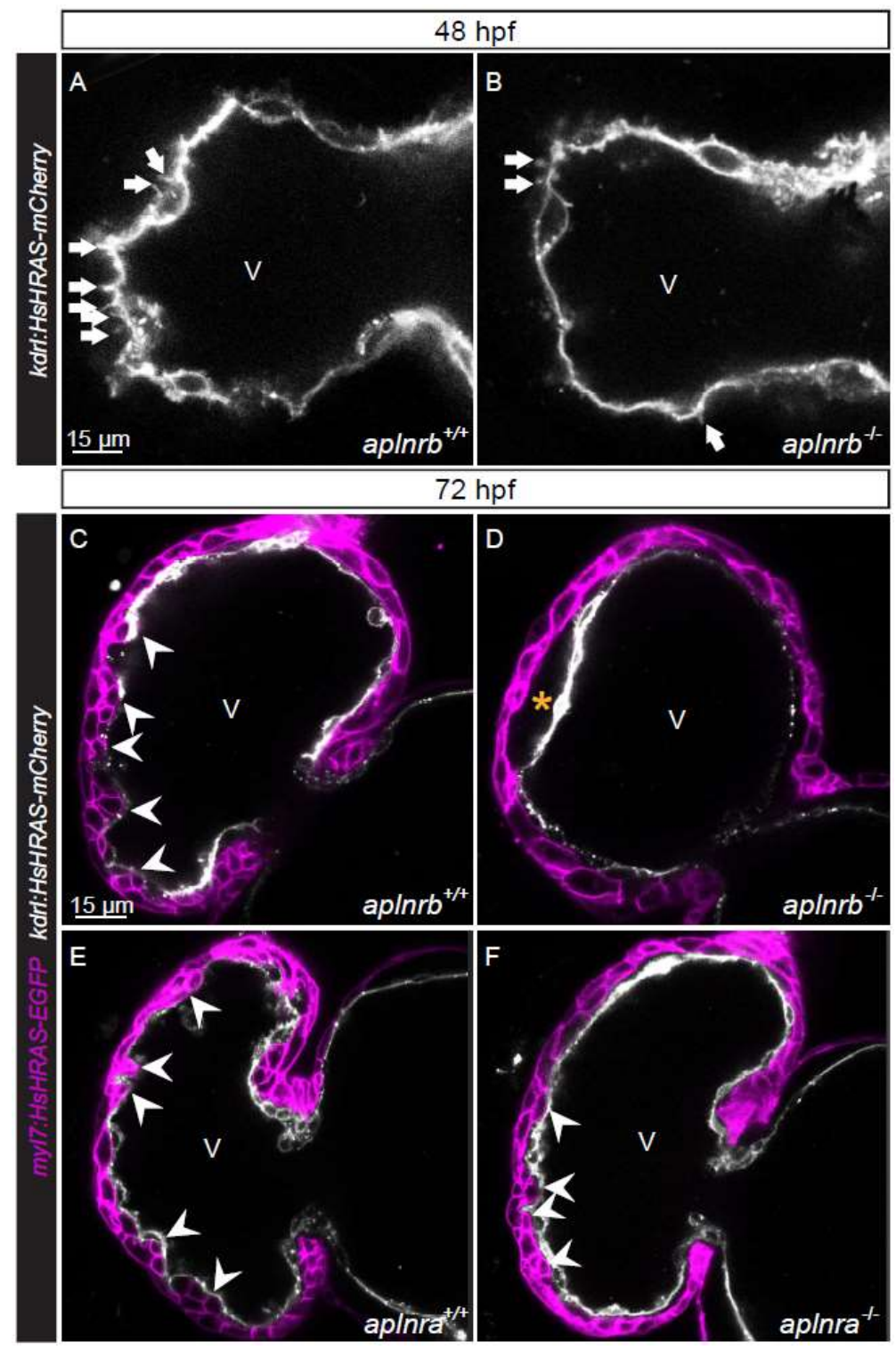

522 Figure 4-figure supplement 2. aplnrb mutants exhibit reduced endocardial protrusion formation and

523 trabeculation and aplnra mutant exhibit a mild reduction in trabeculation. (A-F) Confocal projection images

524 of the heart of $T g$ (kdrl:HsHRAS-mCherry) (A-B) and Tg(myl7:HsHRAS-EGFP); Tg(kdrl:HsHRAS-mCherry) (C-F)

525 zebrafish at 48 (A-B) and 72 (C-F) hpf. (A-B) aplnrb ${ }^{-/-}$embryos exhibit fewer endocardial protrusions (arrows)

526 compared with aplnrb ${ }^{+/+}$siblings (A) at $48 \mathrm{hpf.} \mathrm{(C-D)} \mathrm{ap/nrb}{ }^{-/}$larvae (D) exhibit reduced trabeculation

527 (arrowheads) and thicker CJ (asterisk) compared with aplnrb ${ }^{+/+}$siblings (C) at 72 hpf. (E-F) aplnra ${ }^{-/}$larvae (F)

528 exhibit a mild reduction of trabeculation compared with ap/nra ${ }^{+/+}$siblings (E) at $72 \mathrm{hpf}$. V, ventricle. 



529 Figure 4-figure supplement 3. Apelin signaling regulates CM proliferation in the ventricle. (A-D) Confocal

530 projection images of the heart of $T g(m y / 7: H s H R A S-E G F P)$ larvae at $72 \mathrm{hpf}$. (A-B) Maximum intensity projections

531 of confocal images. (C-D) Mid-sagittal sections of A and B, respectively. ap/n $/$ larvae (D) exhibit fewer

532 proliferating CMs (arrows) in the ventricle compared with $a p / n^{+/+}$siblings (C). (E) Quantification of EdU $\mathrm{CMs}^{+}$in

533 the ventricle of $a p / n^{+/+}$and $a p / n^{-/}$siblings. V, ventricle. Data in graphs expressed as mean \pm SEM. 


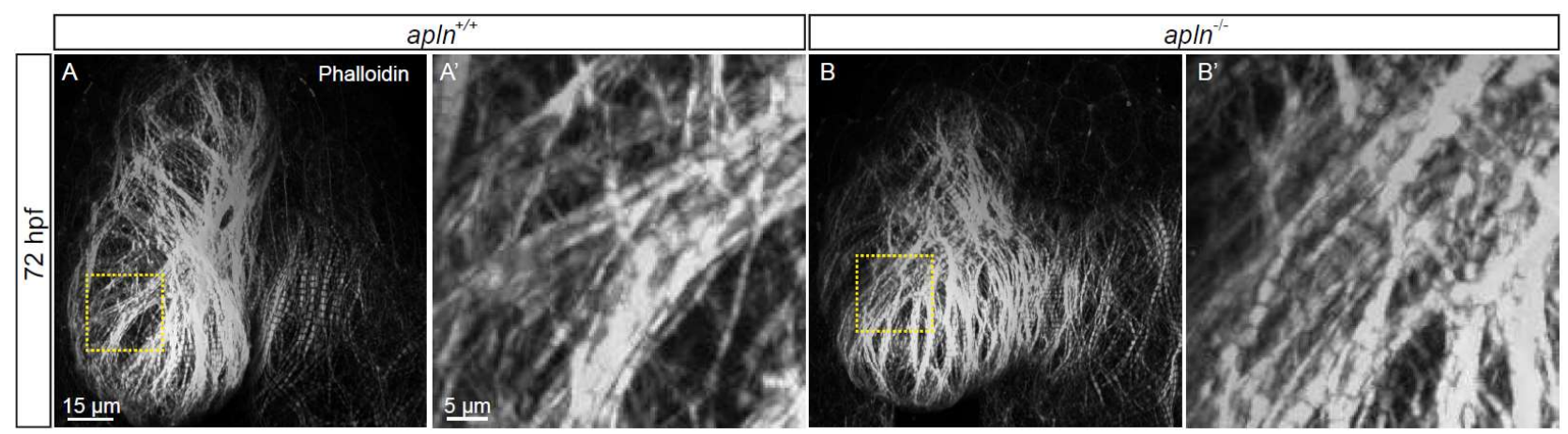

534 Figure 4-figure supplement 4. Wild-type like heart function and sarcomere structure in $a p / n^{-/}$larvae. (A-B)

535 Quantification of heart rate (A) and ejection fraction (B) of $a p / n^{+/+}$and $a p / n^{-1}$ siblings. (C-D) Confocal projection

536 images. Maximum intensity projections of confocal images of the heart of $72 \mathrm{hpf}$ larvae stained with

537 Phalloidin. Sarcomere formation does not appear to be affected in ap/n ${ }^{-/}$larvae (C) compared with ap $/ n^{+/+}$

538 siblings (D) $\left(a p / n^{+/+}, \mathrm{n}=5 ; a p / n^{-/}, \mathrm{n}=4\right)$. V, ventricle. 



539 Figure 4-figure supplement 5. Notch signaling represses endocardial protrusion formation. (A-D) Confocal

540 projection images of the heart of $T g(m y / 7: m C h e r r y-C A A X) ; T g(t p 1-M m H b b: E G F P)(A-B)$ and $T g(c d h 5: G a l 4 f f)$;

541 Tg(UAS:LIFEACT-GFP) (C-D) embryos at $48 \mathrm{hpf}$. (A-B) Treatment with $1 \mu \mathrm{M}$ of the Notch inhibitor R04929097

542 from 24 to $48 \mathrm{hpf}$ blocks the expression of the $T g(t p 1-M m H b b: E G F P)$ Notch reporter in the endocardium. (C-D)

543 Embryos treated with the Notch inhibitor exhibit more endocardial protrusions (arrows). (E) Quantification of

544 the number of endocardial protrusions in the ventricle of DMSO and RO4929097 treated embryos at $48 \mathrm{hpf}$. All

545 images are ventral views, anterior to the top. V, ventricle; A, atrium. Data in graphs expressed as mean \pm SEM. 


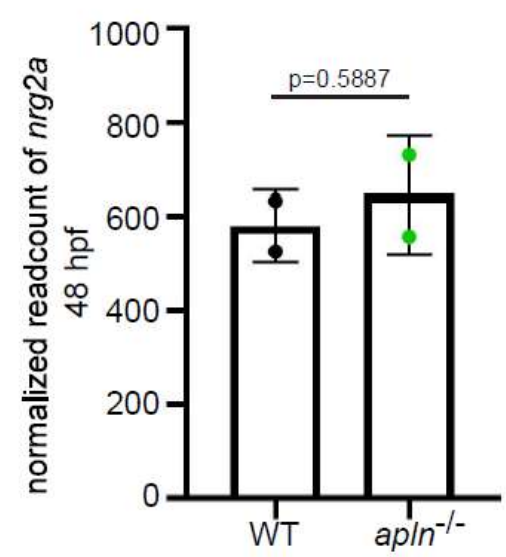

546 Figure 5-figure supplement 1. nrg2a expression does not appear to be affected in apln mutants. $n r g 2 a$ mRNA

547 levels in extracted hearts from wild types and apln mutants at $48 \mathrm{hpf}$ (from RNA-seq). Data in graphs

548 expressed as mean \pm SEM. 


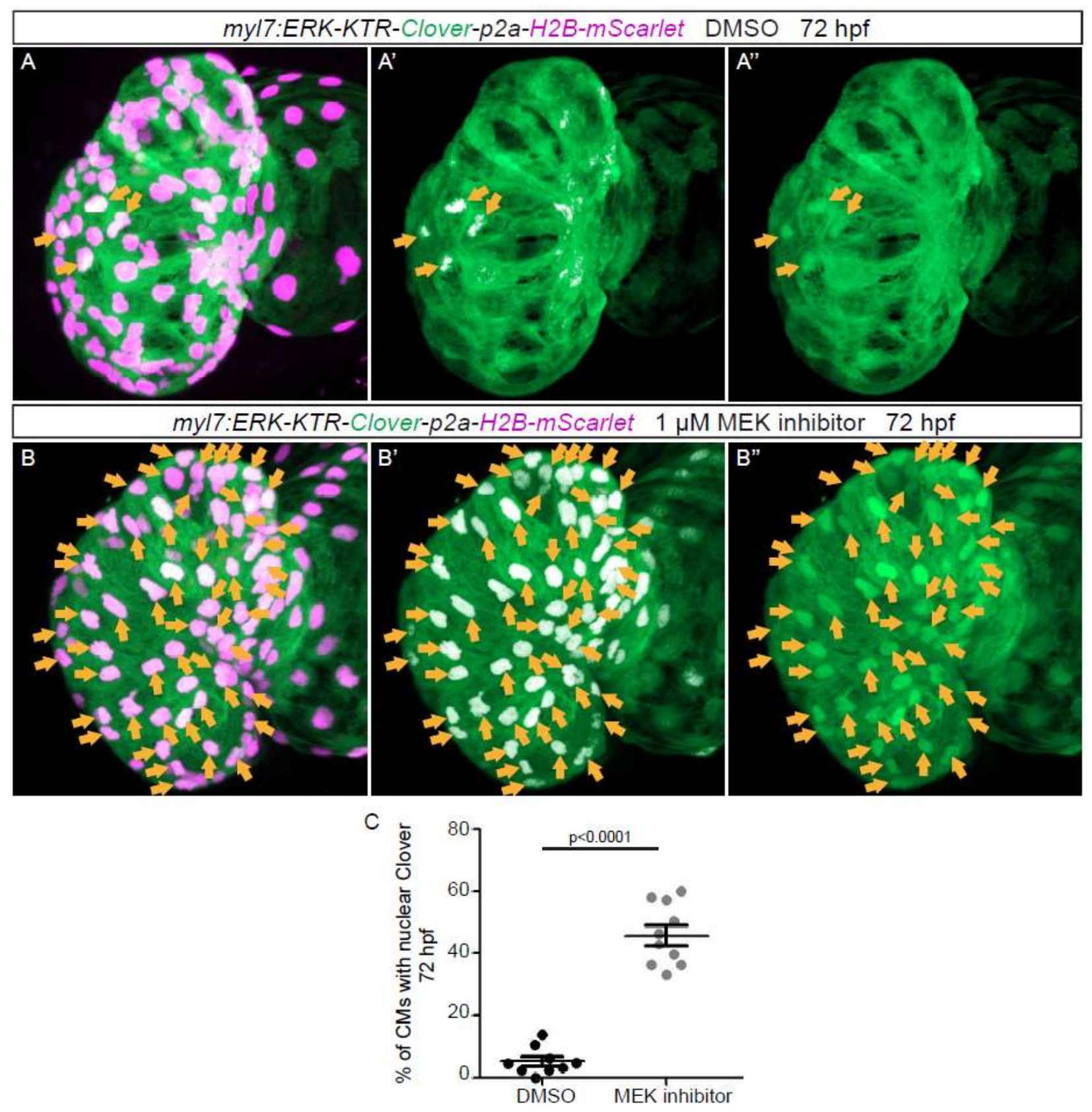

549 Figure 6-figure supplement 1. Erk inhibitor represses the activity of Erk in the Erk reporter line. (A-B)

550 Confocal projection images. Maximum intensity projections of the heart of $T g(m y / 7: E R K-K T R-C l o v e r-p 2 a-H 2 B-$

$551 \mathrm{mScarlet}$ ) larvae at $72 \mathrm{hpf}$. (B) Larvae treated with the Erk inhibitor exhibit an increased number of CMs with

552 inactive Erk signaling (arrows) compared with larvae treated with DMSO (A). (C) Quantification of ventricular

553 CMs with nuclear Clover. All images are ventral views, anterior to the top. V, ventricle. Data in graphs

554 expressed as mean \pm SEM . 

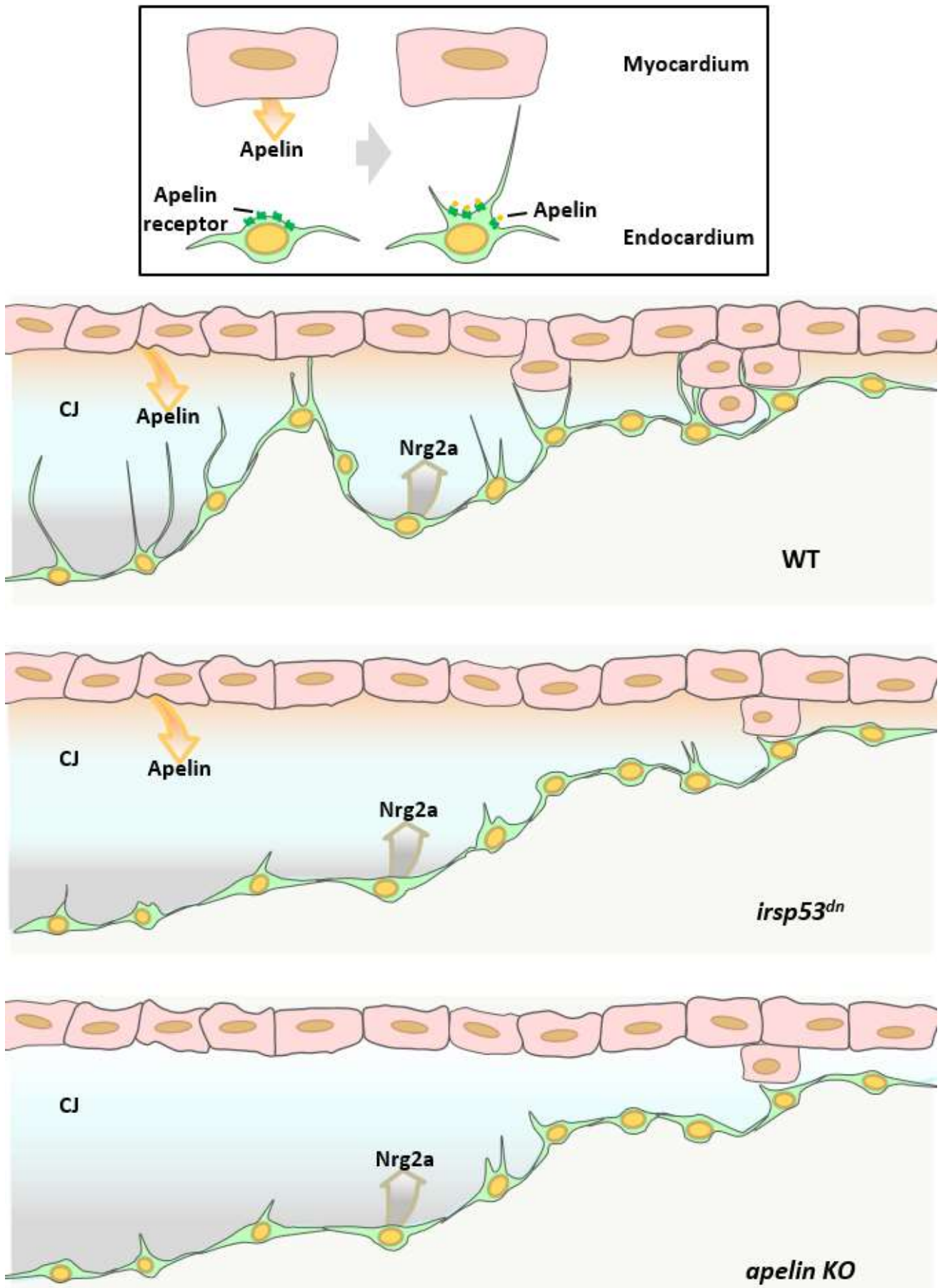

555 Figure 6-figure supplement 2. Schematic model. Schematic model depicts that manipulating the formation of endocardial protrusions results in cardiac trabeculation defects via mediating the function of $\mathrm{Nrg} / \mathrm{ErbB}$

557 signaling. 